\title{
Using Environmental and Biological Indices as Proxies for Egg and Larval Production of Marine Fish
}

\author{
Yvan Lambert \\ Ministère des Pêches et des Océans, Institut Maurice-Lamontagne \\ C. P. 1000, Québec G5H 3Z4, Canada \\ Nathalia A. Yaragina \\ Polar Research Institute of Marine Fisheries and Oceanography \\ 6 Knipovich St., Murmansk, 183763, Russia \\ Gerd Kraus \\ Institute of Marine Sciences \\ Düsternbrooker Weg 20, D-24105, Kiel, Germany \\ Gudrun Marteinsdottir \\ University of Iceland, Department of Biology \\ Grensasvegur 11, 108 Reykjavik, Iceland \\ Peter J. Wright \\ Fisheries Research Services, Marine Laboratory \\ Victoria Road, Aberdeen AB11 9DB, Scotland, United Kingdom
}

\begin{abstract}
Several biological and environmental factors have direct or indirect influence on maturation, fecundity and egg viability of marine fishes. The relationships observed between these reproductive characteristics and specific biological and/or environmental indices may provide alternative methods of estimating annual variations in the reproductive potential of fish stocks in the absence of specific data, or represent a more rapid and less costly method of monitoring egg production. The utility of these relationships to serve as proxies for egg production will depend on the predictive power of the relationships, the effort required to measure selected proxies, the scale of application, and the availability of pre-existing target data. We believe that alternative methods to measure reproductive output could be developed for some reproductive characteristics needed to estimate egg/larval production using data already available. This review, largely based on gadoid fish species, indicates that relationships between indices of nutritional condition (e.g. condition factor, liver index) and potential fecundity meet the criteria of predictability and low effort and thus are candidate proxies for measuring egg production. No relationship examined was a suitable proxy for egg/larval viability and age- and size-at-maturity. The development of alternative measures of reproductive characteristics of fish could result in more precise estimates of reproductive potential of fish stocks that could be used for hindcasting and predicting egg and/or larval production and viability.
\end{abstract}

Key words: age-at-maturity, size-at-maturity, cod, egg larval viability, environmental influences, fecundity, gadoid, flatfish, herring, mackerel, reproductive potential.

\section{Introduction}

Evaluating the reproductive potential of fish stocks requires an understanding of stock-specific reproductive characteristics and the underlying mechanisms. These characteristics include spawner biomass, sex ratio, maturity ogive, potential and realized fecundity, egg viability, and hatching success. Variations in these characteristics can generate important changes in the reproductive potential of a stock with implications for its recruitment success. Fluctuations in these reproductive parameters, however, are very often ignored due to a lack of information at the appropriate frequency and detail. Sampling effort, time of sampling, difficulty of measurement, and cost/benefit considerations have all contributed to the lack of appropriate 
information on these reproductive characteristics (Tomkiewicz et al., 2003).

Age- and size-at-maturity, fecundity, and egg viability each has a large influence on the reproductive potential of a stock yet these characteristics are not routinely measured or used in stock assessments. These characteristics are known to vary between species, stocks, geographical areas, and years and to be influenced by genetic and environmental factors (Alm, 1959; Wootton, 1979; Stearns and Crandall, 1984; Godø and Moksness, 1987; Rijnsdorp, 1993a; Tyler and Sumpter, 1996; Cardinale and Modin, 1999). Many biological and environmental factors will directly or indirectly influence maturation, fecundity, and egg viability (Kjørsvik et al., 1990; Buckley et al., 1991; Rijnsdorp et al., 1991; Nissling, 1994; Tyler and Sumpter, 1996; Chambers, 1997; Kjesbu et al., 1998; Marteinsdottir and Steinarsson, 1998; Cardinale and Modin, 1999; O'Brien, 1999; Lambert and Dutil, 2000). Relationships between biological factors, environmental factors, and reproductive characteristics could potentially be used to predict reproductive potential or components of it. These relationships could thus represent alternative methods of estimating annual variation in reproductive potential. Such methods could be useful when data on maturity, fecundity, and egg viability are absent or they could represent a more rapid and less costly means of monitoring egg production. The availability of historic data on these proxy measures or the simplicity of obtaining new data on these measures could support retrospective or ongoing estimates of the reproductive potential of a stock. These kinds of applications could enhance predictions about stock status and possibly help explain historic trends in stock size.

This paper is primarily based on gadoid fish species but numerous examples on other groups of marine species (e.g. flatfishes, herring (Clupea harengus), mackerel (Scomber scombrus) and anchovies) are provided. It reviews the relationships between biological and environmental factors and reproductive characteristics of fish stocks. Emphasis is given to correlates of maturity, fecundity and egg viability. The possibility of using the environmental and/or biological factors of these relationships as predictors of reproductive potential is evaluated. Important attributes of these relationships, such as their predictive power, simplicity of measurement, scale of application, restrictions in use, and availability of data to support them are also examined.

In this review, the predictive power of a relationship is defined as the minimum difference in the inde- pendent variable $(x)$ that yields significantly different predictions in the dependent variable (y) (McEdward and Morgan, 2001). Two criteria are used to evaluate the relationships. The first is the proportion of the variance in the dependent variable explained by its relationship with the independant variable (i.e. the coefficient of determination, $r^{2}$ ) and the second is the confidence intervals $(\mathrm{CI})$ around the estimated regression parameters. Prairie (1996) noted that the predictive power of regression models with $r^{2} \leq 0.65$ was low and nearly constant but increases very rapidly for higher $r^{2}$ values. An increase in $r^{2}$ from 0.2 to 0.5 increased the resolution power by about $28 \%$, whereas increasing $r^{2}$ from 0.6 to 0.9 doubled it. On this basis, models explaining $>65 \%$ of the variance could potentially be used as proxies. Moreover, the rapid increase in the predictive power for relationships resulting in $r^{2}>0.65$ justifies the search for additional explanatory variables. The overlap of $95 \%$ CI around the predicted values for different values of the explanatory variable $(x)$ was suggested as a measure of the predictive power of a regression (McEdward and Carson, 1987; McEdward and Morgan, 2001). Overlap of the CI for two values of the independent variable $(x)$ indicates that the two corresponding predicted values are not significantly different. The predictive power is determined by comparing the minimum difference in the explanatory variable $(x)$ needed to yield significant differences in predicted values $(y)$ to the range of the explanatory variable (McEdward and Morgan, 2001). For example, the predictive power is reasonably good for models requiring explanatory variable differences of $16-17 \%$ of the observed range.

\section{Maturation of Fish}

Fish ontogeny is usually divided into different stages which may be viewed in the context of gonadal development. These stages are: egg and larval development, pre-reproductive, reproductive and postreproductive periods (Rass, 1948; Kryzhanovsky, 1949; Shatunovsky, 1980; Balon, 1984). The pre-reproductive period is characterized by protoplasmatic growth and the formation of oogonii and oocytes. Further gonadal development, i.e. vitellogenesis, ovulation, fertilization, as well as previtellogenesis before the second and subsequent spawning, occurs in mature fish. The duration of the pre-reproductive period can differ widely within and among species. Maturation, which is partly under genetic control, influenced largely by environmental conditions (Alm, 1959; Stearns and Crandall, 1984; Godø and Moksness, 1987; Rijnsdorp, 1993a; Cardinale and Modin, 1999). Changes in ageand size-at-maturity have been linked to growth during 
the pre-reproductive period (Rijnsdorp, 1993a; Godø and Haug, 1999; Walsh and Morgan, 1999) and it is generally assumed that maturation will be attained at some size or age threshold. Stearns and Crandall (1984) argued, however, that maturation occurs along a trajectory of age and size, and that maturity was neither length-nor age-specific in the strict sense. Long-term changes in age- and size-at-maturity are also expected, based on life history theory, to respond to growth and survival of juvenile and adult fish (Gadgil and Bossert, 1970; Stearns and Crandall, 1984).

Predicting age- and size-at-maturity requires the knowledge of the processes controlling maturation both in terms of the proximate factors influencing the physiological decision to mature and of the selection of this life history trait based on life history theory. Commonly used indices of maturation are the mean length, weight, and age at which $50 \%$ of individuals from the population become mature. Usually these indices are derived from models that are fitted to data (Welch and Foucher, 1988; Rijnsdorp, 1993a, b; Trippel et al., 1997a; Saborido-Rey and Junquera, 1998; Cardinale and Modin, 1999). These indices vary among and within species. Within species, length- and ageat-maturity will vary between different geographical areas and time periods (Table 1). Sex-specific age- and size-at-maturity may also vary within populations of the same species and estimates are available in the scientific literature for various stocks. These estimates may, however, be difficult to compare across studies since they might refer to different stock areas within a stock, historical periods and groupings (e.g. sexes combined or males and females analysed separately).

The following sections examine the mechanisms influencing the age and size at which fish mature and the relationships between these maturation traits and various biological and environmental factors. These correlations are evaluated for their potential to predict the proportion of mature fish. If their potential is high, the biological and environmental factors can be considered as candidate proxies for the estimation of the spawning biomass and egg production of stocks.

\section{Mechanisms Influencing Maturation}

Critical periods in maturation. A number of hypotheses have been proposed to explain when a fish matures for the first time. These hypotheses pertain to either the attainment of a critical size, the rate of acquisition of surplus energy, growth rate, or condition. As a fish develops through the juvenile stage it enters a period of liability wherein maturation may be induced but is not necessarily predetermined. This period of susceptibility is commonly referred to as a 'critical period'. This critical period may also be applied to repeat spawners because reproduction may ensue or be stopped depending on the condition of the fish prior to the spawning season.

It is generally assumed that maturation is bounded by some size or age threshold (Nikolsky, 1969; Roff, 1982; Thorpe, 1986; Rijnsdorp, 1993a). To the degree that the threshhold size is near the actual size, fast growing individuals are likely to mature earlier than slow growing individuals. For example, in the period 1960-90 $L_{\text {mat }}$ ( $L_{\text {mat }}$ corresponding to the length at which $50 \%$ of the fish became mature) for North Sea plaice, Pleuronectes platessa, was $5.8,4.2$ and $3.9 \mathrm{~cm}$ lower than in the period 1904-11 at ages 4, 5 and 6, respectively. The shift in maturation envelope to smaller sizes coincided with an increase in growth rate of juvenile and adult plaice (Rijnsdorp, 1993a). Rapidly growing individuals of cod (Gadus morhua) and halibut (Hippoglossus hippoglossus), which attain maturity at a younger age than slower growing individuals, mature at a shorter size as well (Godø and Haug, MS 1998).

Policansky (1983) proposed that maturity was not triggered by the attainment of a certain size or age when experiencing stable and benign conditions, but that fish that are growing rapidly should mature as soon as they are physiologically able to do so. Under hatchery conditions, this phenomenon is seen to occur causing high proportions of fish to enter maturity at young ages. In male salmonids maturity can be attained in the first autumn, when the fish are only 6 months of age (Thorpe et al., 1982). Laboratory experiments with Atlantic cod have shown that nutrition during the pre-reproductive period influences the age at maturation. Cod fed ad libitum began to mature by the end of their second year and spawned during their third year (Braaten, 1984). Thorpe (1986) suggested that growth rate was acting to modify the age at maturation and proposed a growth model for Atlantic salmon, Salmo salar, that included a sensitive period during which maturation was triggered. In this model, fish that experience good environmental conditions have high growth rates during their critical period which encourages early maturity. The critical period for salmonids appears to occur in autumn (Thorpe, 1994) before significant changes in gonad mass and increases in hormone levels. In the subsequent period of increasing day length the following spring, fish express either further maturation or fail to mature and spawn in the upcoming spawning season (Thorpe et al., 1998). 
TABLE 1. Age $\left(A_{50}\right)$ and size $\left(L_{50}\right)$ at $50 \%$ maturity for male $(\mathrm{M})$ and female (F) Atlantic cod from different geographic areas of the Northern Atlantic Ocean.

\begin{tabular}{|c|c|c|c|c|c|}
\hline Area & Sex & $A_{50}$ & $L_{50}$ & Years & Reference \\
\hline \multirow[t]{4}{*}{ Baltic Sea } & M & 2.8 & 37.7 & 1988 & Cardinale and Modin (1999) \\
\hline & $\mathrm{F}$ & 3.7 & 49.6 & & \\
\hline & M & 1.5 & 27.0 & 1996 & Cardinale and Modin (1999) \\
\hline & $\mathrm{F}$ & 2.7 & 33.2 & & \\
\hline \multirow[t]{4}{*}{ Labrador/Grand bank } & M & 4.8 & 45.5 & 1979 & Taggart et al. (1994) \\
\hline & $\mathrm{F}$ & 6.2 & 55.0 & & \\
\hline & M & 4.0 & 37.0 & 1993 & Taggart et al. (1994) \\
\hline & $\mathrm{F}$ & 5.4 & 45.8 & & \\
\hline \multirow[t]{3}{*}{ Georges Bank } & $M \& F$ & 2.1 & 43.1 & $1986-94$ & Hunt 1996 \\
\hline & M & & 42.8 & & \\
\hline & $\mathrm{F}$ & & 43.6 & & \\
\hline Scotian Shelf & M & 5.4 & 52.0 & $1959-64$ & Beacham (1983) \\
\hline \multirow[t]{3}{*}{ Subdiv. 4Vn } & $\mathrm{F}$ & 6.3 & 55.0 & & \\
\hline & M & 2.8 & 36.0 & $1975-79$ & Beacham (1983) \\
\hline & $\mathrm{F}$ & 2.8 & 34.0 & & \\
\hline \multirow{4}{*}{ Subdiv. 4Vs } & M & 5.4 & 47.0 & $1959-64$ & Beacham (1983) \\
\hline & $\mathrm{F}$ & 5.2 & 44.0 & & \\
\hline & M & 2.7 & 38.0 & $1975-79$ & Beacham (1983) \\
\hline & $\mathrm{F}$ & 2.9 & 38.0 & & \\
\hline \multirow[t]{4}{*}{ Div. 4W } & M & 4.7 & 46.0 & $1959-64$ & Beacham (1983) \\
\hline & $\mathrm{F}$ & 5.0 & 52.0 & & \\
\hline & M & 2.7 & 37.0 & $1975-79$ & Beacham (1983) \\
\hline & $\mathrm{F}$ & 2.9 & 39.0 & & \\
\hline \multirow[t]{4}{*}{ Div. $4 \mathrm{X}$} & M & 4.8 & 57.0 & $1959-64$ & Beacham (1983) \\
\hline & $\mathrm{F}$ & 3.7 & 46.0 & & \\
\hline & M & 2.8 & 45.0 & & \\
\hline & $\mathrm{F}$ & 2.9 & 45.0 & $1975-79$ & Beacham (1983) \\
\hline Faroes & $\mathrm{M} \& \mathrm{~F}$ & 2.7 & 44.0 & $1973-89$ & Jakupsstovu and Reinert (1994) \\
\hline \multirow[t]{2}{*}{ Subdiv. 3Ps } & $\mathrm{M} \& \mathrm{~F}$ & 7.0 & & 1981 year-class & Chen and Mello (1999) \\
\hline & $\mathrm{M} \& \mathrm{~F}$ & 5.0 & & 1990 year-class & Chen and Mello (1999) \\
\hline Subdiv. 3Pn & $\mathrm{M} \& \mathrm{~F}$ & $6.6-6.8$ & & $1947-50$ & Fleming (1960) \\
\hline \multicolumn{6}{|l|}{ Northern Gulf St. } \\
\hline Lawrence Subdiv. & M & 5.1 & 46.0 & $1947-66$ & Wiles (1968) \\
\hline 3Pn-Div. 4RS & $\mathrm{F}$ & 6.1 & 50.0 & & \\
\hline \multirow[t]{2}{*}{ Flemish Cap } & $\mathrm{F}$ & 3.8 & 51.7 & 1992 & Saborido-Rey and Junquera (1998) \\
\hline & $\mathrm{F}$ & 3.2 & 39.1 & 1995 & Saborido-Rey and Junquera (1998) \\
\hline \multirow[t]{2}{*}{ Northeast Arctic } & $\mathrm{M} \& \mathrm{~F}$ & 9.5 & & 1923-24 year-classes & Jørgensen (1990) \\
\hline & $\mathrm{M} \& \mathrm{~F}$ & 7.0 & & 1975-76 year-classes & Jørgensen (1990) \\
\hline Northeast Arctic & $\mathrm{M} \& \mathrm{~F}$ & & 72.0 & $1980 \mathrm{~s}$ & Ponomarenko and Yaragina (1994) \\
\hline \multirow[t]{2}{*}{ North Sea } & M & & 53.0 & $1968-73$ & Oosthuizen and Daan (1974) \\
\hline & $\mathrm{F}$ & & 60.0 & & \\
\hline
\end{tabular}

In winter flounder, Pseudopleuronectes americanus, a non-reproductive state in adult fish may occur if feeding is restricted prior to and immediately after the spawning season (Burton, 1994). Histological observations of the ovary indicate that the nonreproductive state occurs as a result of fish failing to undergo exogenous vitellogenesis, suggesting that nutritional status acts as a control mechanism early in the gametogenic process. Fish with high post-winter condition may become reproductive despite being starved during this critical period which suggests that current nutritional status also acts as a regulator of reproduction (Burton, 1994).

A circannual endocrine-based switch from reproductive dormancy to active gonadal development, is 
suspected to exist for female walleye, Stizostedion vitreum, (Henderson et al., 1996). Two separate critical periods involving an endocrine switch were identified in the gametogenic cycle of these fish. The first occurs in August after the replenishment of energy reserves from visceral fat, while the second occurs in October when females, even immature ones, exhibited a transient development of ovarian tissue with energy derived from these visceral fat deposits. For both critical periods the transition to reproductive maturation appears to be triggered by the energetic status of the fish.

Metabolism and rate of gonadal development. Reproductive expenditures can represent 10 $22 \%$ of the annual energy budget (Shatunovsky, 1980; Eliassen and Vahl, 1982; Jobling, 1982). Gonadal weight can reach $40 \%$ of the total body weight in some species of fish (Wootton, 1979; Tyler and Sumpter, 1996). The gametes commonly develop over an extended time period which can last 4 to 6 months (Koshelev, 1984; Kjesbu et al., 1991). During this period of gametogenesis, nutrients are transferred to the gametes. Fish typically exhibit seasonally large gonads and therefore, high energetic expenditures are required by the individual during gametogenesis, even for young individuals, in which no regular sexual cycle is yet established (Shatunovsky, 1978). The proportion of energy invested in reproduction increases from the first to the second-third spawning, and then stabilizes reducing only in fish at the maximum possible age (Shatunovsky, 1980). In some species the allocation of energy to gonads occurs simultaneously with somatic growth. In other species, there is an annual cycle of energy allocation to somatic growth and energy storage with a subsequent transfer of nutrients to gonads (Wootton, 1979). A reduction in metabolic rate can influence these processes and causes a delay in the development of oocytes at the previtellogenesis phase (Koshelev, 1984).

Prior to reaching maturity, the accumulation of energetic resources (protein and lipids) will be highly important. Changes in the metabolic activity and chemical composition of the different tissues (i.e. accumulation of specific fractions of proteins and lipids, phosphoproteins, phospholipids, esters of stearins and others) will be observed in relation to the transformation and transport of the different biochemical molecules necessary for the development of gonads (Shatunovsky, 1980). Part of the variability observed in energy allocation reflects differences in species life history and local responses to specific environments.
Central to these allocation patterns are lipid reserves which connect environmental resources to various uses of this acquired energy by the organism such as for reproduction (Adams, 1998). In some fish, individual adults must attain a minimum fat content before maturation is initiated (Shulman, 1974). For example, Atlantic salmon, Salmo salar, returning from sea in the spring appear to require a minimum fat content of about $12 \%$ if they are to spawn the following autumn (Rowe et al., 1991).

Some fish with a normal one-year maturity cycle fail to spawn in all spawning seasons (Messiatzeva, 1932; Walsh et al., MS 1986; Burton, 1991; Oganesyan, MS 1993; Burton et al., 1997; Rideout et al., 2000). This phenomenon was also noted in cod from the Northeast Arctic (Marshall et al., 1998). The absence of spawning is believed to occur when stored energy reserves are too low. Laboratory experiments on cod from the Gulf of St. Lawrence demonstrated that fish maintained at a low level of condition during maturation did not spawn (Lambert et al., 2000). Atresia of developing oocytes or delayed development of oocytes may explain the suspension of the normal maturation cycle.

Ultimate influences. Long-term variations of mean age- and size-at-maturity have been recorded for most major commercial fish species. The majority of publications demonstrate a decrease of $A_{50}$ and $L_{50}$ in populations in recent years, compared to earlier periods (Wiles and May, 1968; Oosthuizen and Daan, 1974; Beacham, 1983; Ponomarenko and Yaragina, MS 1994; Taggart et al., 1994; Hunt, 1996; Trippel et al., 1997a; Cardinale and Modin, 1999; Chen and Mello, 1999) (Table 1). However, the role of genetic and non-genetic factors in explaining these changes is largely unknown.

According to life history theory (Gadgil and Bossert, 1970) an organism encountering conditions that results in slower growth should alter its age- and size-at-maturity along a trajectory that minimizes the reduction in fitness caused by slower growth and smaller size. Importantly, the trait under selection is the combination of age- and size-at-maturity (Stearns and Crandall, 1984). Life history models have considered fitness consequences of maturity in terms of the differences in growth and survival of juveniles and adults. Hence, selection for delayed maturation could arise because it results in a gain in fecundity or because it results in reduced juvenile mortality, or both. Such models have explained a large portion of the observed variation in age at maturity between species (e.g. Roff, 1984) and suggest that there may be age-size 
maturity trajectories that vary with growth and stagedependent mortality (Stearns and Crandall, 1984). Work by Reznick and colleagues on guppies (Poecilia reticulata) provides one of the few empirical studies of a genetically based response to changes in stageand size-specific mortality (Reznick et al., 1990; Reznick et al., 1997). Their work made use of the differences in size-specific mortality caused by two natural predators, pike cichlid (Crenicichla alta) which mostly consume large mature guppies and a killifish (Rivulus hartii) that consume small immature ones. By moving guppies from sites with the cichlid to sites with the killifish they were able to manipulate stage-specific mortality. After 11 years, or 30-60 generations, there were genetic differences in age- and size-at-maturity between guppies in the original and introduced sites. Guppies matured both later and at larger sizes, when living with the killifish than the cichlids. A life history response to stage-specific mortality is likely to occur in other fish populations including those subjected to commercial harvest.

For most demersal fish species, increases in the proportion of mature fish at smaller sizes is consisent with a selective fishery that favours reproduction by early maturing fish. The long-term historical variations in size- and age-of-maturity of the cod stocks during the $20^{\text {th }}$ century have been linked to increased exploitation, followed by density-dependent effects and/or possible genetic changes. Borisov (1978) used the example of a hypothetical year-class of cod, consisting of early ( $6 \mathrm{yr})$, medium ( $8 \mathrm{yr})$ and late (11 yr) maturing subgroups of fish in order to evaluate the effects of changes in size-specific contribution of adults to the reproductive output of the population. Increased exploitation resulted in a reduction in the contribution of the medium and especially late maturing fish to reproduction, and an increase in the contribution of early maturing fish. It is still unclear, however, whether these traits are inherited or whether they are simply a result of phenotypic plasticity.

Sexual dimorphism in maturity rates and sex ratio. Whilst stock assessments usually combine sexes when considering spawning stock biomass, there are often gender related differences in maturity. Very often, males and females differ in their rates of maturation. In most species males become mature at an earlier age and smaller size than females (Oosthuizen and Daan, 1974; Taggart et al., 1994; Ajiad et al., MS 1998; Cardinale and Modin, 1999). In the Baltic Sea cod stock, differences in age- and size-at-maturity $\left(A_{50}\right.$ and $\left.L_{50}\right)$ between males and females are of 1 year and $12 \mathrm{~cm}$, respectively. Male cod from the Northwest Atlantic (NAFO Div. 4Vn) also mature at a lower age and smaller size than females from this stock $(0.9 \mathrm{yr}$ and $3 \mathrm{~cm}$, respectively) (Beacham, 1983). In the North Sea, the size of cod at $50 \%$ maturity is $7 \mathrm{~cm}$ smaller in males than in females. Significant differences in the growth rates of males and females in relation to maturity are also noted in flatfish (Haug and Tjemsland, 1986; Godø and Haug, MS 1998). This phenomenon of maturation of females at later ages and larger sizes is probably related to the greater expenditures of energy required for ovarian development compared to testicular development.

In some species, males mature later than females. This is observed especially among species having a more elaborate and costly spawning behaviour. For example, males of Neogobius melanostomus in the Azov Sea (Kostyuchenko, 1961) and males of some salmonids, e.g. Oncorhynchus nerka mature at older ages than females (Altukhov and Varnavskaya, 1983; Altukhov and Salmenkova, 1991). In both species males are responsible for protecting their offspring.

Sex ratio is an important population feature which affects the evolutionary trends in life history traits (Zamakhaev, 1964; Nikolsky, 1969; Geodakian, 1974, 1981). Males often predominate populations in variable or stressful environments, especially at the margins of the species' geographic range. In contrast, females often predominate populations from stable environments. In variable environments, the long-term optimum sex ratio favours males and a similar trend is observed even when environmental variation is of short duration (Makeeva and Nikolsky, 1965). The sex ratio can vary between populations, year-classes, and even within a single year-class. The first fish to mature and enter the spawning stock are likely to be males because they usually mature earlier than females. Thus, the sex ratio of a population will be skewed towards males especially as an abundant year-class enters maturity. As the year-class advances, the proportion of males will decrease, and hence the older age groups and largest individuals of the stock will be comprised mainly of females. Considerable variation in sex ratio was observed for the mature population of Northeast Arctic cod reflecting large differences between year-classes (especially in the 1960s and early-1970s). Survey data and commercial landings of cod in Lofoten, Norway, indicated that the sex ratio (male:female) of the mature part of the population during 1989-97 was in many cases greater than 2:1 (Ajiad et al., MS 1998). These variations in sex ratios emphasize the importance of estimating reproductive potential annually. 
Relationships between biological factors, environmental factors, and maturity

Variations in age- and size-at- maturity within and between stocks. Considerable variation in the age- and size-at-maturity has been observed among geographical areas, time periods, and sexes both between and within stocks (Table 1). Attempts to explain and predict the proportion of a year-class maturing have considered various biological and environmental factors, such as genetic variation, growth rate, stock size, and temperature. Highly prognostic relationships, however, were found in only a few cases.

Mean age and size at 50\% maturity for cod have been observed to vary among areas or populations by as much as 1.5 to 9.5 years of age and 27 to $72 \mathrm{~cm}$ in length (Table 1). The size range at which maturity is occurring within a population is also variable. For example, the transition from immature to $100 \%$ mature occurred over a $40-\mathrm{cm}$ length interval for both male and female cod from the Scotian Shelf (NAFO, Subdiv. $4 \mathrm{Vs}$ ) during 1959-64. This same transition occurred over a shorter length interval $(20 \mathrm{~cm})$ in the period between 1975 and 1979 (Beacham, 1983). In the Northeast Arctic cod stock, first maturing males and females were recorded at $37 \mathrm{~cm}$ and $42 \mathrm{~cm}$, respectively, but immature individuals were also observed for lengths of up to $100 \mathrm{~cm}$ (Glebov, 1963). Female cod from the Baltic Sea mature between 2 and 6 yr of age while males mature for the first time between 1 and $5 \mathrm{yr}$ (Alexeyev and Alexeyeva, 1998). Cod in the North Sea also mature between 2 and 6 yr (Rijnsdorp et al., 1991). The age range over which cod mature is very large in some stocks. In Northeast Arctic cod, for example, all fish from the 1923-24 year-classes were immature at $7 \mathrm{yr}$ while $100 \%$ maturity was reached by fish of $13 \mathrm{yr}$ of age, indicating that the age at first maturity for these year classes was extended over as much as a 6 yr period (Jørgensen, MS 1988, 1990).

Genetic variation. Variations in age- and size-atmaturation can reflect differences in the genetical composition of populations or reflect phenotypic plasticity in response to variations or changes in environmental conditions (Rijnsdorp, 1993a). Growth rate, ageat-maturity, and the degree of genome heterozygosity were correlated in salmonids, genus Oncorhynchus (Altukhov, 1994, 1998). Small-size, early maturity and short lifespan of males was expressed in populations with high levels of genetic heterozygosity. Heterozygosity was low for large males. Females of intermediate age, growth rate, and length were characterized by an intermediate level of heterozygosity (Altukhov and
Varnavskaya, 1983). High individual heterozygosity corresponds to a high rate of development and maturation, early age at first reproduction, and a reduced lifespan for males. A selective fishery towards largesize males could modify the long-term genetic diversity and result in an increase of small, early maturing, and more heterozygous males in spawning stocks. Thus, changes in genotype frequencies over time associated with exploitation could affect the maturation profile (Trippel, 1995). Similar mechanisms regulating growth and maturation are probably found in other species. Genotypic differences in somatic growth and in the age-at-maturity of cod from Trondheimsfjord and Oslofjord were observed using the polymorphic haemoglobin locus HbI (Mork et al., 1984). Sexual differences, however, in the genotype frequencies with respect to growth and age-at-maturity were observed. The age of first spawning as estimated by otolith spawning marks, was significantly lower for the HbI22 genotype males (females were not examined). Laboratory experiments with coastal and Northeast Arctic cod indicated, however, that differences in growth and age at first spawning reflected differences in the environment rather than genetic differences (Godø and Moksness, 1987).

Growth strategies. Lapin and Yurovitsky (1959) distinguished different relationships between growth and maturation which they related to environment and ontogeny. The main types of relationships observed between growth and maturation in the literature are, fast growth rate and early maturation $v s$ slow growth rate and delayed maturation. Fast growth rate and delayed maturation are less common but have been observed for Neogobius melanostomus in the Sea of Azov (Kostyuchenko, 1961), and in sockeye salmon (Altukhov and Varnavskaya, 1983). Dwarfism, which is characterized by slow growth and early maturation, was observed in populations of different fish species (Ricker, 1981; Koshelev, 1984; Nelson and Soulé, 1987). A summary of available data on the effect of growth on maturation does not reveal a consistent pattern (Table 2). The proportion of North Sea plaice maturing at $4 \mathrm{yr}$ of age was directly related to the cumulative somatic growth of 2-3-year-old fish (Rijnsdorp et al., 1991). Increased growth over the lifetime of a cohort and increased growth in the year before maturation were related to different measures of the maturation of males and females (Table 2) in yellowtail flounder, Pleuronectes ferruginea, on the Grand Bank (Walsh and Morgan, 1999). Similar relationships were not found, however, in Northeast Arctic haddock, Melanogrammus aeglefinus, North Sea cod and sole, Solea solea (Kovtsova, MS 1987; Rijnsdorp et al., 


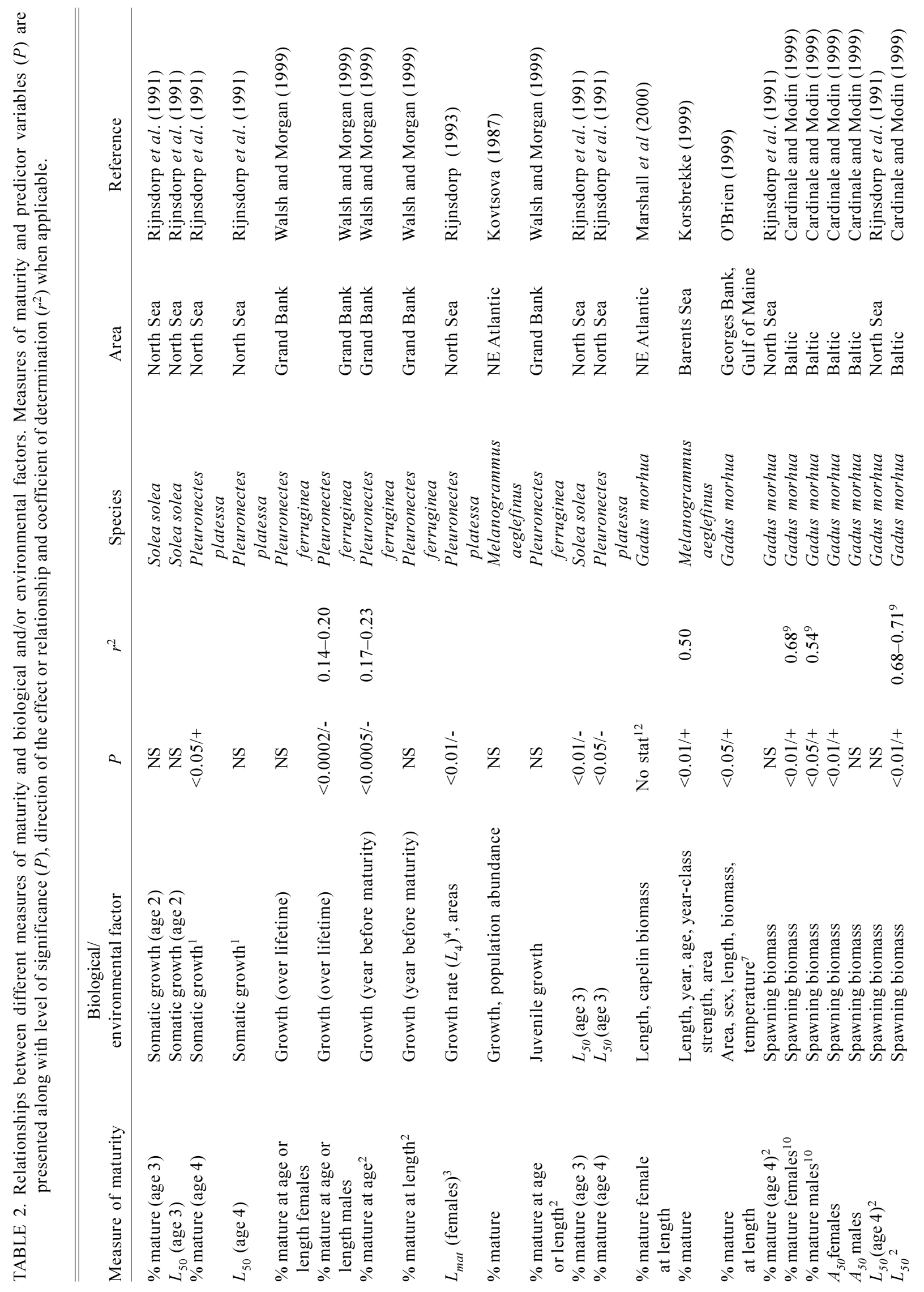




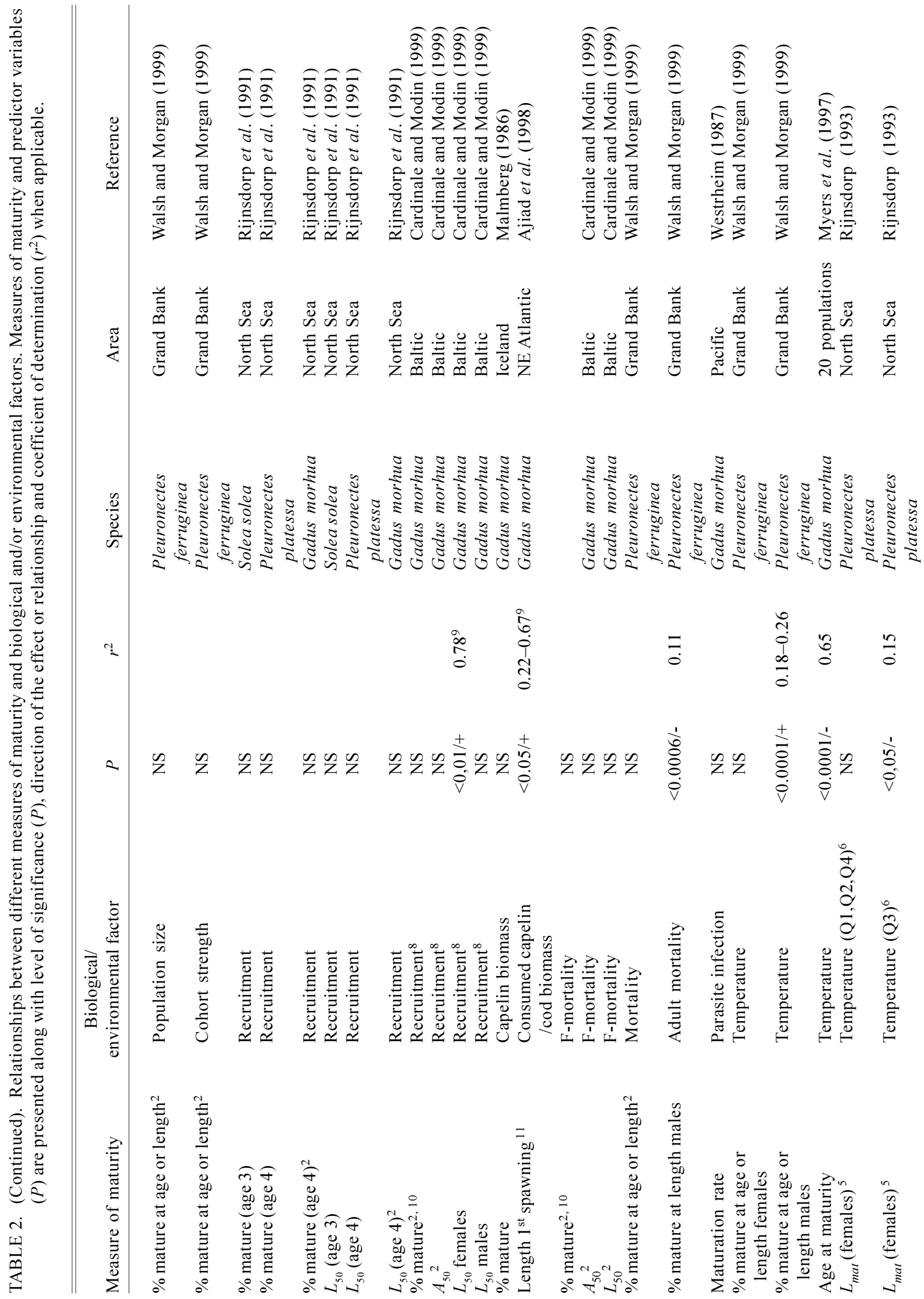




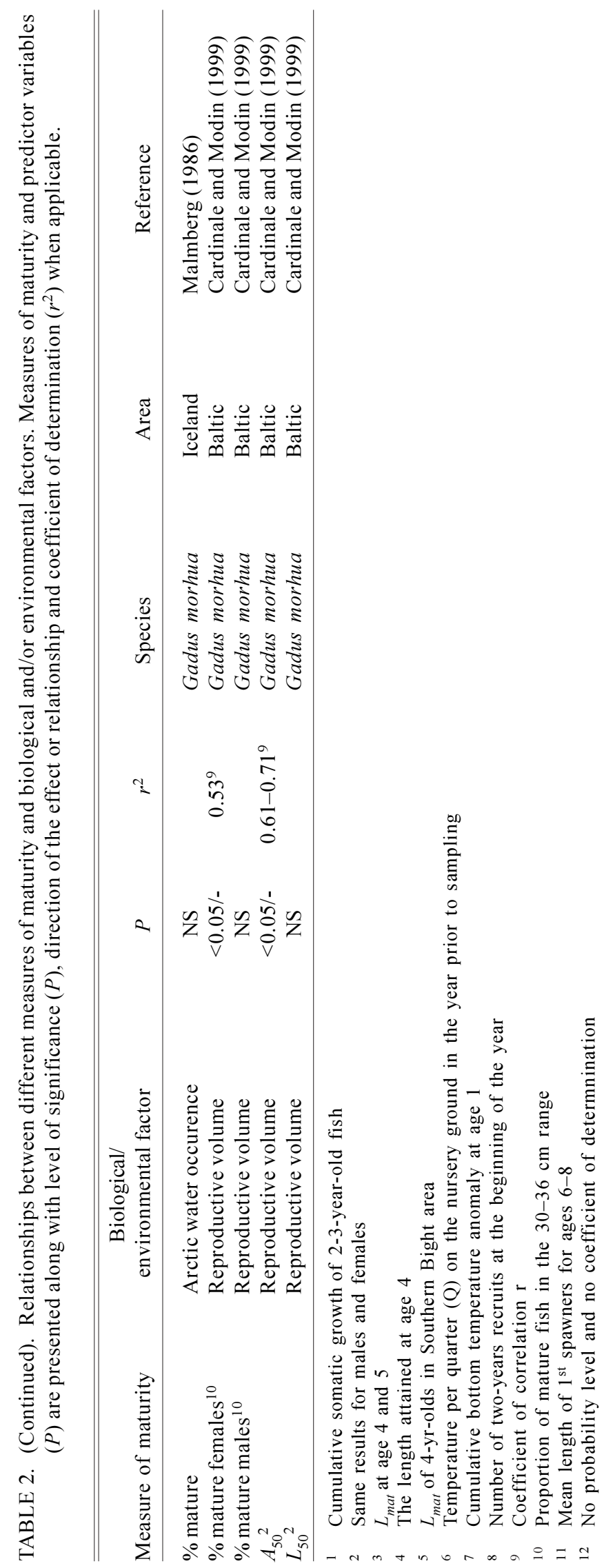


1991). Regression models including multiple effects also provide indirect evidence of the effect of growth on maturation. Significant length effects in multiple regression models describing the variation in the proportion of mature fish for Barents Sea haddock (Korsbrekke, 1999) and Georges Bank and Gulf of Maine cod (O'Brien, 1999) indicate that growth has an effect on maturation since length will contain information on growth rate.

Density-dependent effects. Positive relationships between the size-at-maturity and the spawning biomass for some species and stocks provide evidence of some form of density-dependence effect on maturation (Table 2). In Baltic cod, a significant relationship was observed between size-at-maturity (50\% maturity) and spawner biomass (Cardinale and Modin, 1999). Stock biomass also explained a significant proportion of the variability in the sexual maturation of cod from Georges Bank and Gulf of Maine (O'Brien, 1999). Possible density-dependent effects were also examined by comparing year-class strength to the rate of maturation. For example, the very large 1990 year-class of haddock from the Barents Sea appeared to be characterized by a lower proportion of mature fish by length and age (Korsbrekke, 1999). No well-defined relationships were found, however, between the proportion of mature fish and year-class abundance for North Sea plaice (Rijnsdorp et al., 1991) and yellowtail flounder (Walsh and Morgan, 1999).

Feeding conditions. Maturation is likely to be affected by the feeding conditions experienced by fish in the previous season. Thus, it was suggested that changes in the maturation of Northeast Arctic cod of ages 6-8 were due to the per capita consumption of capelin (a major prey) (Ajiad et al., MS 1998). A significant increase was observed in the portion of mature fish of both sexes with increasing ratio between the consumption of capelin by cod and cod biomass (C/B ratio) (Table 2), but the relationship decreased with increasing age. The same type of relationship was demonstrated for Icelandic cod; growth rate, and proportion mature being directly related to the capelin biomass and/or to the amount of Arctic water running in the north of the Icelandic shelf (Malmberg, 1986).

Hydrography. Temperature conditions may influence size and/or age at maturation. Latitudinal differences in temperature were accompanied by variations in the length at maturity of female plaice in the North Sea (Rijnsdorp, 1993a). A negative correlation was observed between $L_{m a t}$ and the average temperature in the third quarter of the previous growing season (Table 2). A strong positive correlation $(r=0.98 ; P<0.01)$ between mean weight at age 4 and average bottom temperature for 17 different cod stocks of the North Atlantic indicates the important influence of temperature on cod growth (Brander, 1994). Temperature also accounted for a significant proportion of the variation in the maturation of male and female cod from Georges Bank and Gulf of Maine (O'Brien, 1999). The examination of several populations of cod from the North Atlantic revealed a significant negative correlation between age at maturity and temperature (Myers et al., 1997) (Table 2).

The mean age at maturity of Baltic Sea cod was shown to be negatively related to the reproductive water volume of the sea (the volume of the sea with suitable salinity, oxygen, and temperature for reproduction) but no such relationships were found for size at maturation (Cardinale and Modin, 1999). Suitable levels of oxygen (i.e. $>2 \mathrm{ml} / \mathrm{L}$ ) and salinity (i.e. $>11 \%$ ) could be considered as an index of stress affecting the body mass allocated to the gonads, assuming that in poor spawning conditions, young and small female Baltic cod will postpone maturation.

Light and photoperiod. The manipulation of light conditions in tank experiments has demonstrated the effect of this factor on maturation. Experiments on farmed cod with different photoperiods and light intensities indicate that continuous light delayed sexual maturation and improved growth of both sexes (Hansen et al., 1995; Dahle et al., 2000; Karlsen et al., 2000). Light intensity also had an effect on sexual maturation and growth (Dahle et al., 2000).

Diseases. Fish diseases may also influence the maturation rate. For example, delays in the maturation of Pacific cod (Gadus macrocephalus) were found to be caused by parasite lesions (Westrheim, 1987).

Pollution. Disturbance of the fish reproductive system has been observed in areas suffering from heavy pollution. The most common types of disturbance in fish reproductive function are the asymmetric development of gonads and structural deformation, early maturation, resorption of gametes at all developing stages, missed spawning and reduction in fecundity (Shatunovsky et al., 1996). Hermaphrodism, sterility of specimens, and mass atresia (abortive ovulation) observed long before spawning during accidental discharge of pollutants are also reported for systems polluted with heavy metals and oil products. The 
long-term effect of oil spills on reproduction has been shown in marine fishes (Deniel, 1984; Brule, 1987).

\section{Evaluation of potential proxies of maturity}

Few studies show significant relationships between maturation rates and biological and environmental variables, although the overall number of such studies is increasing. The predictors of maturity rates are likely to differ for each species and stock and vary over time.

The highest correlations between maturity rates and biological and environmental factors occurred in Baltic cod $(r=0.71-0.78$; Table 2). The relationships between maturation parameters and biological and environment factors were weak in the other species and stocks examined. Thus, present data support only qualitative trends with respect to biological and environmental factors.

Observed indices of fish maturation are associated mainly with indices of fish size (length). Nevertheless, as this review has highlighted, maturity is not simply related to the attainment of a certain length or age. Other significant factors include fish condition, environmental conditions, stock density-dependent effects and long-term changes in stage-dependent mortality.

Each ecosystem has its own variables that might influence the maturation process. In ecosystems characterized by a complicated trophic structure without dominating species (e.g. the North Sea) strong relationships between any food indices and maturity are not to be expected. Simple, food limited ecosystems, (e.g. arcto-boreal regions such as the Barents Sea and the Icelandic shelf), may be more likely to exhibit relationships between trophic and maturity variables. The quantity and quality of the food consumed, metabolic patterns, and the amounts of accumulated proteins and fat are probably directly involved in the triggering of maturation in all species, but these data are difficult to obtain routinely. In arcto-boreal ecosystems, indices of food supply and feeding may serve as indirect indices to relate maturation to the quantity and quality of food consumed. Common indices available include the abundance and biomass of prey species, the availability of prey, degree of stomach fullness, daily and yearly consumption, frequency of occurrence of abundant food items in stomachs of predators, and percentage of empty stomachs.

Biological and physiological indices related to growth and energy reserves such as increases in length and mass, Fulton's condition factor, fat content (e.g. liver index in gadoids, fatness of muscular tissue in clupeids and degree of fatness of viscera in walleye), and indices of protein and fat metabolism could potentially be used to predict fish maturation. The utility of these indices could be limited, however, by their inherent variability, the genetic variability of the population, and environmental variation between areas (see the fecundity section below). Areas with very specific environments (e.g. Baltic Sea) could possibly limit generalization. For example, variability in salinity and oxygen content which are specific to the Baltic Sea appear to be important predictors of the maturation of cod in that area. However, relationships derived for Baltic cod are unlikely to be applicable to many other areas where critical levels for salinity and oxygen are not encountered.

\section{Potential use of biological and environmental factors as proxies of maturity}

Maturation rates in fish populations are subject to considerable fluctuations. Age- and size-at-maturity in each stock may be shaped by the hydrographic and feeding conditions experienced by the developing young fish and maturing individuals. Fishing, pollution, hydroelectric power stations, and water storage basins among other human activities may also affect maturation rates.

Further experimental and correlative investigations of maturation of fish are needed in order to identify physiological mechanisms associated with maturation, as well as the basis of variation in fish maturation rates in the wild. Such information is warranted as, in the absence of regular field observations, erroneous assumptions of fixed values of maturity ogive parameters will lead to biased estimates of spawning stock biomass.

\section{Fecundity}

The pattern of energy allocation to reproduction varies considerably among fish species and is linked to life history trade-off between egg size and egg number (Einum and Fleming, 2000). High numbers of relatively small eggs appear to be the favoured strategy among many marine teleosts (Jennings et al., 2001).

The number of eggs per female has been variously defined in the fisheries literature (Murua and SaboridoRey, 2003). Potential fecundity is defined as the number of vitellogenic oocytes in the prespawning ovary. Realized fecundity represents the number of eggs that are spawned. The difference between potential and realized fecundity is due to the number of atretic eggs 
(Ma et al., 1998). Batch fecundity refers to the number of hydrated oocytes in the ovary of batch spawners at the time of sampling (Yamada et al., 1998) or to the number of eggs spawned in a batch (Hislop et al., 1978; Kjesbu, 1989). Fecundity can be expressed as absolute or relative fecundity. Absolute fecundity represents the total number of eggs and relative fecundity is the number of eggs per unit body weight (Tyler and Sumpter, 1996).

Realized or annual fecundity is determined by the number of eggs released in each spawning (batch size) and the number of spawnings (batches) during each season. As the batch size is related to the volume of the body cavity, the annual fecundity is, in most fishes, strongly related to body size (Wootton, 1999). Wootton (1992) evaluated fish size in 238 species and found that total volume was approximately equal to fish length ${ }^{3}$. Similarly, fecundity is often estimated by fish length raised to the 3-5 power (Marteinsdottir and Begg, 2002).

Environmental conditions and nutritional status are known to potentially have strong modifying effects on fecundity in fish. The relative importance of environmental and genetical factors in producing interindividual, inter-annual, and geographical variation in fecundity is not, however, well known (Wootton, 1979). Although little research has been conducted on the genetics of fecundity in fish, it is likely that, as in mammals, some specific genes are playing a role in the determination of fecundity (Tyler and Sumpter, 1996). Besides genetic constraints, level of energy reserves and food intake and some environmental factors have been related to fecundity. Fish condition, feeding level, growth rate, prey abundance and temperature are some of the biological and environmental factors that have been examined in relation to fecundity. Fish condition is a general term used to define the well-being of a fish. Several measures have been used as indicators of fish condition (Bolger and Connolly, 1989). Fulton's condition factor $(k)$ is probably the most common measure that has been used (Bolger and Connolly, 1989; Blackwell et al., 2000). The formula for calculating $K$ is:

$$
K=\left(W / L^{3}\right)-100
$$

where $W$ is total weight in grms, $L$ is length in $\mathrm{cm}$, and 100 is a constant used for scaling purposes. Different formulations of the condition factor based on somatic weight and gutted weight are also found in the literature (Millner et al., 1991; Lambert and Dutil, 1997a, b). Other indices have also been used as indicators of fish condition. These include liver index (hepatosomatic index), body water content, visceral-somatic index, gut index, protein-energy ration, calorific values of fish tissues, including protein and lipid fractions, and partial condition factors (Bolger and Connolly, 1989).

The following section reviews the relationships that have been observed between biological and environmental factors and fecundity. Subsequent to this we examined the possibility of using these relationships as proxies of fecundity in the estimation of egg production of fish stocks.

\section{Mechanisms influencing fecundity}

Fecundity is believed to be constrained by genes and modulated by somatic growth and/or nutrition (Tyler and Sumpter, 1996). Energy devoted to egg production will come from accumulated energy reserves or directly from feeding (Fig. 1). Food consumption will determine the amount of energy that can be diverted to reproduction and several environmental factors (e.g. temperature, salinity, and dissolved oxygen) will influence the quantity and availability of food. The strength of the correlations between these environmental and biological factors will influence the predictive power of each of these factors. For example, seasonal variation in feeding and ovarian development could affect relationships between indices of energy reserves and fecundity. Ovarian development occurring during a period of partial or complete fasting could lead to stronger relationships between condition, energy reserves, and potential fecundity than one for a period of feeding. In the first case, energy invested in egg production will come from energy reserves accumulated during periods of abundant food supply while in the second case, energy invested in egg production will be obtained directly from feeding. Although potential fecundity and temperature have been correlated in many species, the covariation between temperature and other factors might question the utility of these relationships in some cases. In Pacific herring, Clupea harengus pallasi, it was hypothesized that the correlation between sea temperature and potential fecundity was the result of a direct influence of temperature on gonadotropin regulation and consequently on pre-ovulatory atresia (Tanasichuk and Ware, 1987). A significant correlation between potential fecundity and temperature was also observed in Northeast Arctic cod (Kjesbu et al., 1998). Potential fecundity was also correlated with population biomass of Barents Sea capelin. There were, however, indications that temperature and capelin biomass were correlated with each other. In such circumstances, relationships may not hold in all environmental conditions, as temperature will not be 


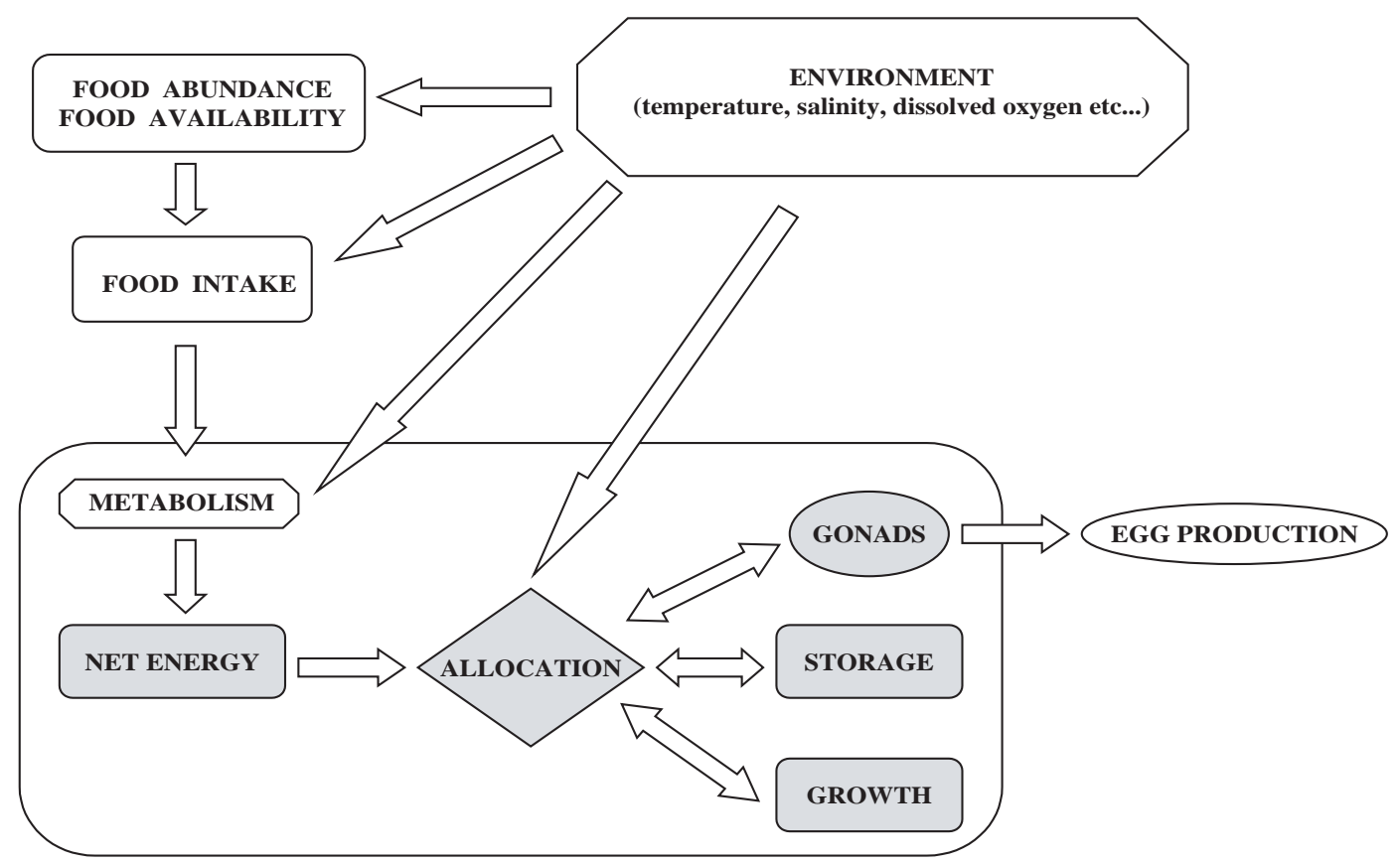

Fig. 1. Schematic representation of the possible sequence and interdependence of factors influencing gonad development and egg production. Inter-relationships between these environmental and biological factors will determine the rules of allocation and/or reallocation of energy in reproduction (fecundity).

the only factor regulating capelin abundance. Predictive models are likely to be more enduring when they are based on a well known underlying mechanism.

Fish size is the factor that most influences potential fecundity. The relationship between potential fecundity and length is usually described by a curvilinear relationship $\left(Y=a X^{b}\right)$ with values of $b$ typically ranging between 3 and 5 . The values of the parameters describing the relationships can vary among species, populations, geographic areas, and years. The coefficient of determination $\left(r^{2}\right)$ for each relationship can vary according to the range in potential fecundity observed for fish of the same size and also to the range of fish size. For example, Kjesbu et al. (1998) observed that the $r^{2}$ for the relationship between potential fecundity and length for Northeast Arctic cod dropped considerably when larger fish were excluded from the relationship. Thus, variations in the predictive power of fecundity-length relationships can represent genetic, biological, environmental, or even sampling effects.

\section{Correlations between biological factors, environmen- tal factors, and fecundity}

Atlantic cod. Condition factor has been widely used as an indicator of energy reserves in many spe- cies. In Atlantic cod, condition factor and hepatosomatic index have been shown to be reliable indicators of total energy content and lipid content, respectively (Lambert and Dutil, 1997a, b). Many studies of cod have reported correlations between these indicators of energy reserves and potential and/or realized fecundity (Table 3 ). In laboratory experiments, cod with high condition factors produced more previtellogenic oocytes and used a larger fraction of these during vitellogenesis. Actual fecundity was between 20 and $80 \%$ of potential fecundity depending on the nutritional status of the fish, and a significant positive relationship between the percentage of previtellogenic oocytes and Fulton's condition factor was observed (Kjesbu et al., 1991). Laboratory experiments conducted with cod from the northern Gulf of St. Lawrence also indicated that female cod with low energy reserves were investing less energy in egg production (Lambert and Dutil, 2000). Realized fecundity and total egg dry weight were significantly reduced in females with low condition factors. A multiple regression model indicated that length and condition factor explained $72 \%$ of the variability observed in realized fecundity. Forty-nine percent of this variability was explained by female length, while condition factor explained $23 \%$ of the variability. Potential fecundity of Atlantic cod held in sea cages in Newfoundland was greater than in wild cod of the same 
length captured in the same area (Wroblewski et al., 1999). Differences in potential fecundity were apparently related to better nutritional condition of the caged fish which had a higher nutritional condition (Fulton's condition factor) than wild cod. Moreover, differences in the mean relative fecundity of caged cod from two different locations were directly related to nutritional condition (t-test, $P=0.015$ ).

There are also indications that condition has a significant effect on potential fecundity in wild cod (Table 3 ). Significant variations in condition and fecundity of cod were observed in the 1990s in the northern Gulf of St. Lawrence (Lambert and Dutil, 1997b; Lambert et al., 2000). Significant relationships between potential fecundity, length, and condition factor were observed for maturing females in 1995 and 1998. The higher condition factors observed for pre-spawning females in 1998 than in 1995 were associated with higher potential fecundities in 1998 (Lambert et al., 2000). Variation in fecundity of Northeast Arctic cod was also related to condition (Kjesbu et al., 1998; Marshall et al., 1998). A multiple regression analysis applied to pre-spawning females captured in 1989 indicated that total length and liver weight had direct effects on potential fecundity (Kjesbu et al., 1998). Interannual variation in potential fecundity was directly related to condition of females. The significant changes in annual regressions of whole body weight on total length between 1986 and 1991 were used to define the 1987 spawners as in poor condition and those in 1991 as in good condition. Estimated potential fecundity (regressions between potential fecundity and total length) was found to be $44 \%$ lower in 1987 than in 1991. Potential fecundity of Northeast Arctic cod was also observed to be significantly correlated with environmental temperature and capelin biomass (Kjesbu et al., 1998). The potential fecundity of a standard female of $90 \mathrm{~cm}$ was estimated from regressions between potential fecundity and total length using data from 1986 to 1996 . This potential fecundity was correlated to the 6-month mean temperature before spawning and the ratio of Barents Sea capelin biomass to Northeast Arctic cod spawner biomass (Table 3 ). Temperature and capelin biomass were, however, also correlated with each other (Kjesbu et al., 1998).

At the population level, Marshall et al. (1998) observed a significant effect of both length and condition on the relative fecundity of Northeast Arctic cod. Condition was estimated as the mean hepatosomatic index value of the population in the year before spawning. Interannual variation in the mean hepatosomatic index value was also correlated to the abundance and availability of capelin in the Barents Sea (Marshall et al., 1998; Marshall et al., 1999; Yaragina and Marshall, 2000).

In Icelandic cod, condition (in addition to length or weight) was shown to be significantly related to potential, relative, and batch fecundity (Marteinsdottir and Begg, 2002). Generally, more variation was explained by the hepatosomatic index than by Fulton's condition factor and, in some years, more variation in relative fecundity was explained by the hepatosomatic index than by length. Up to $92 \%$ of the variation in potential fecundity was explained by length and condition (Marteinsdottir and Begg, 2002). In Baltic cod, temperature and individual condition factor at sampling had a significant though minor correspondence to individual potential fecundity (Kraus et al., 2000). In another study, the variability in potential fecundity of Baltic cod was unrelated to female condition (Kraus et al., MS 1997). For each sampling year analysed, the residuals of the fecundity-length relationships were unrelated to Fulton's condition factor and the hepatosomatic index. Growth anomaly and ambient water temperature, however, explained a substantial amount of the observed variance in the annual average relative fecundity of Baltic cod (Kraus et al., 2000). The multiple regression model explained $66 \%$ of the variability and was able to give a reasonable prediction of the inter-annual variation in relative fecundity. Using another model based solely on the relative prey availability estimated by the sprat and herring age- 0 and age- 2 biomass per unit of mature cod resulted in a higher proportion of the variability in relative fecundity being explained (Kraus et al., 2002). The exponential function relating relative fecundity to a prey availability index explained $72 \%$ of the variance in relative fecundity of Baltic cod (Table 3 ).

Haddock. Laboratory experiments on haddock clearly indicated that fish kept on high rations produced more eggs (realized fecundity) than those on low rations (Hislop et al., 1978) (Table 3). Net energy intake (kcal per day) and final condition factor were also higher in fish with high rations. Parasitic infection had a significant effect on the potential fecundity of wild populations of haddock (Hislop and Shanks, 1981). Infections by the copepod Lernaeocera branchialis significantly reduced the potential fecundity of haddock in the northern North Sea. Comparisons of the fecundity-length relationships indicated that infected fish produced approximately 20\% fewer eggs than uninfected fish of the same length. Infected fish were also lower in weight at length and condition $(\mathrm{P}<0.01)$ than were uninfected fish (Hislop and Shanks, 1981). 


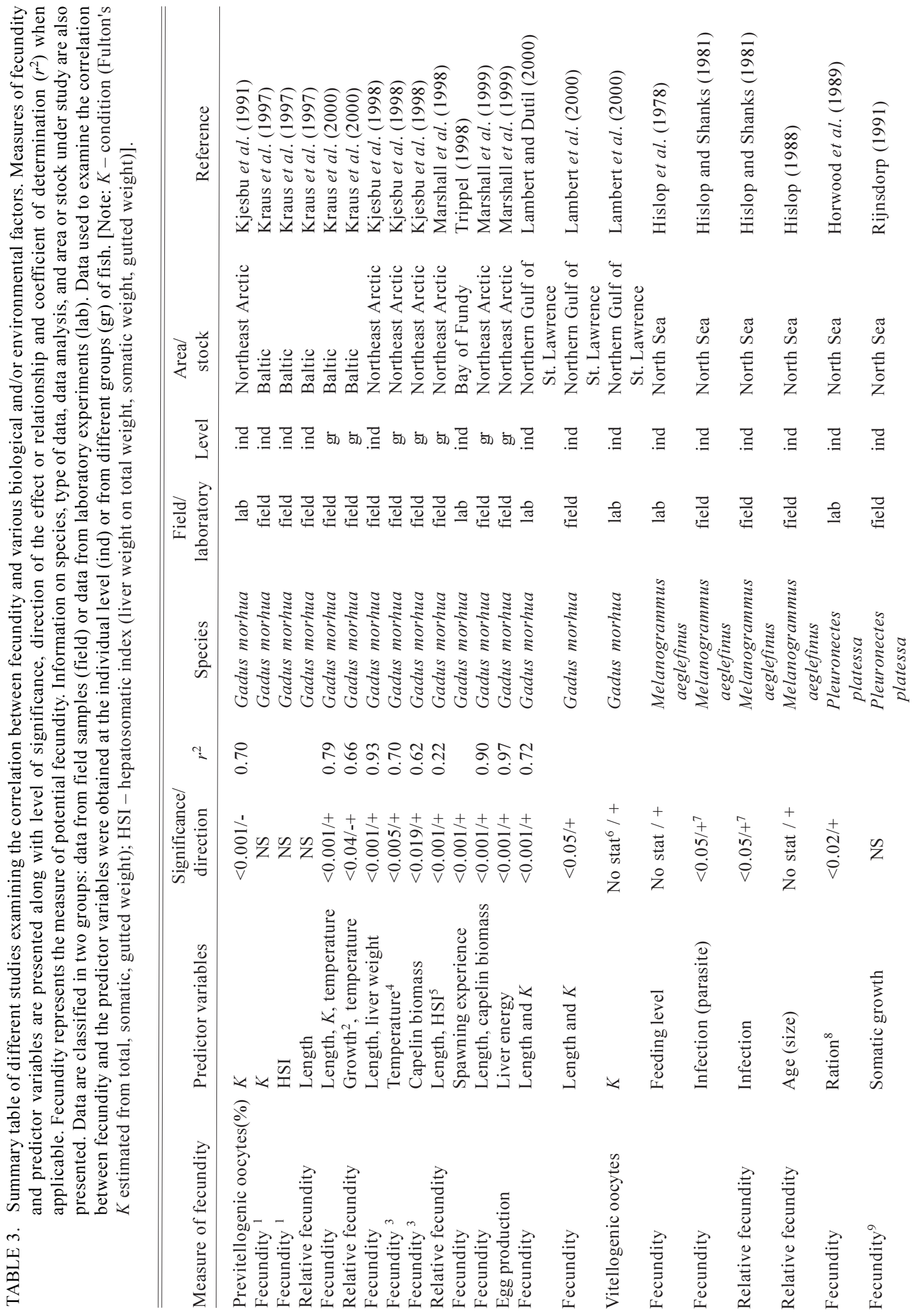


LAMBERT et al.: Environmental and Biological Indices as Proxies

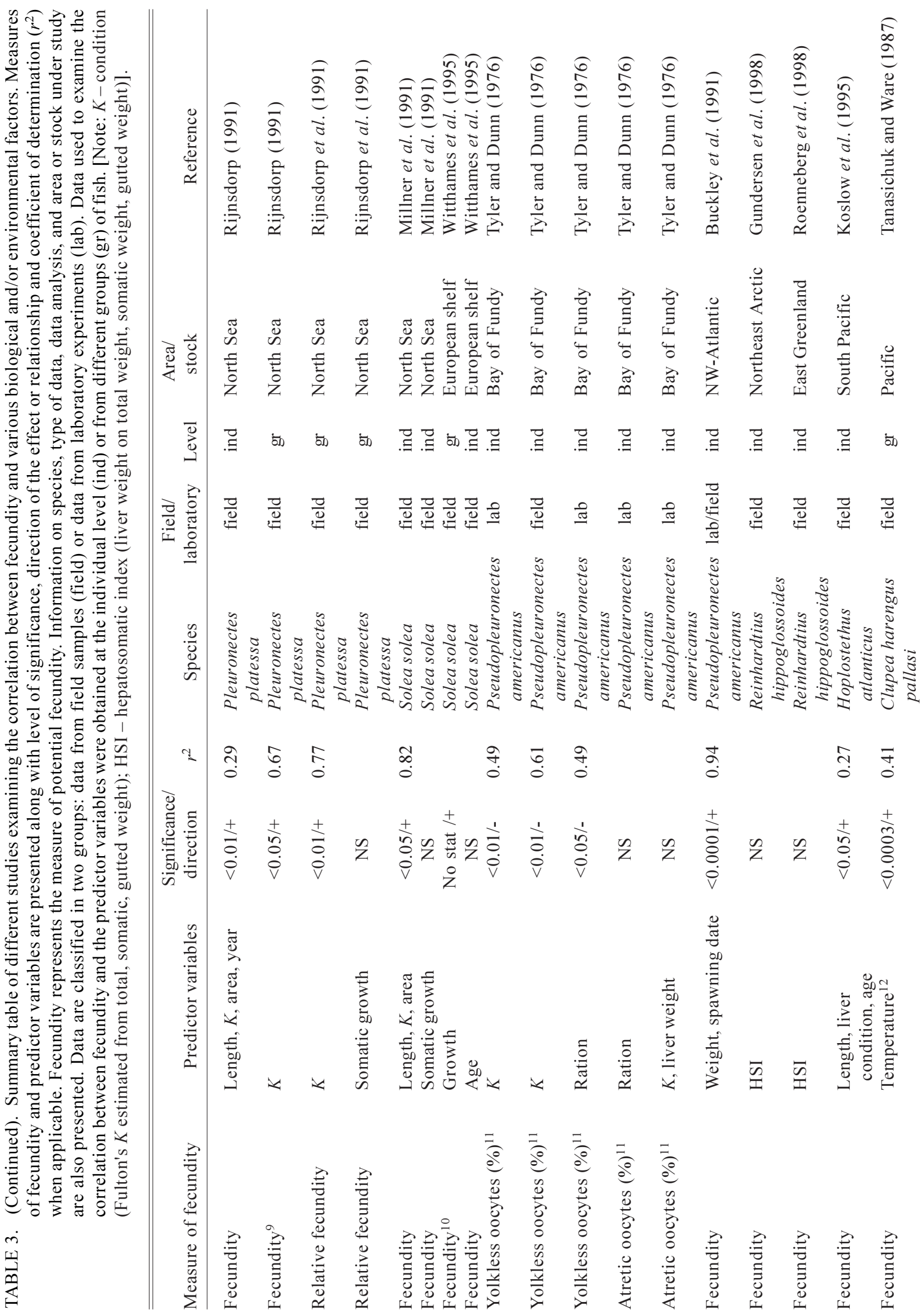




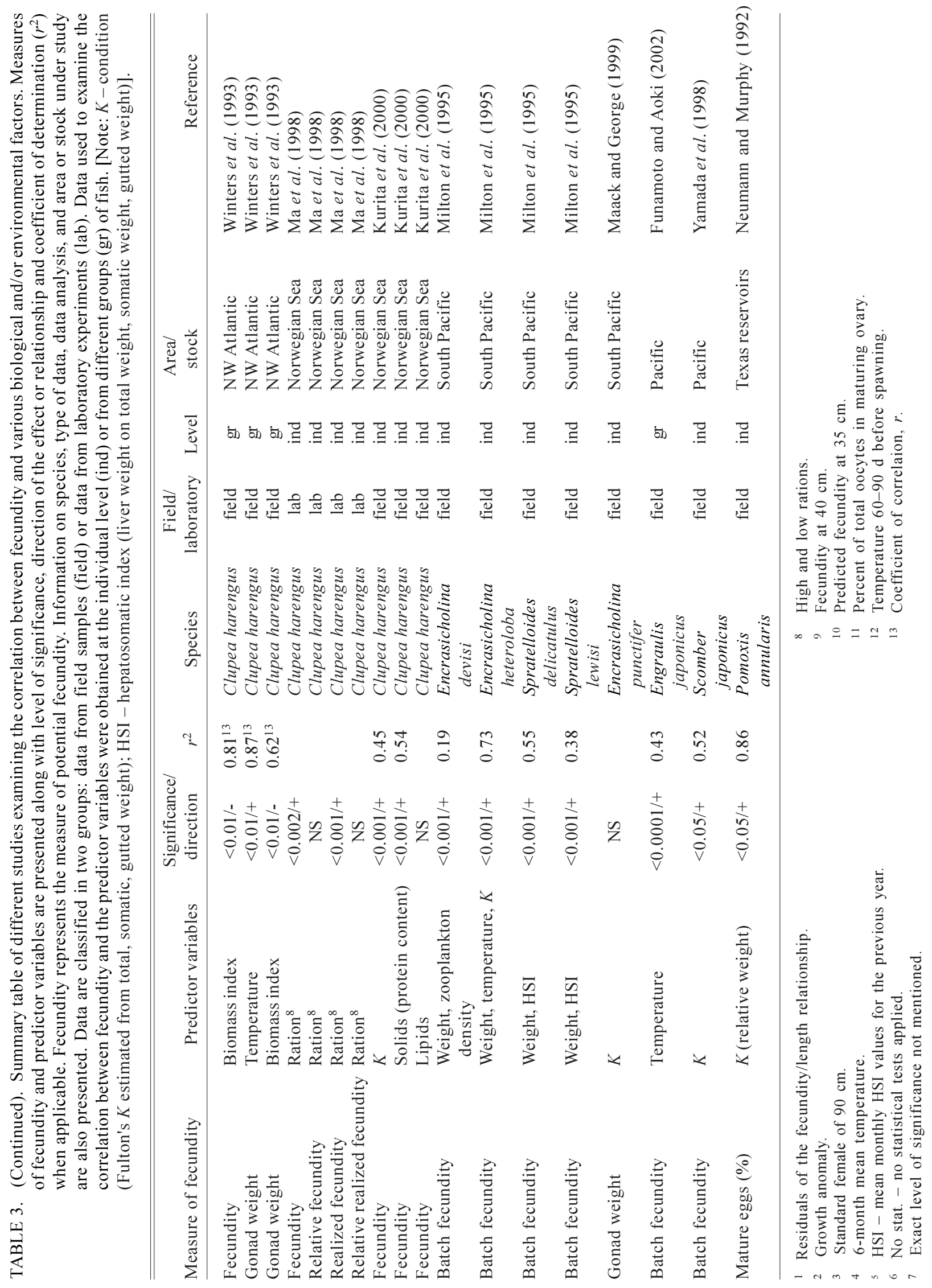


The relative fecundity of 2-year-old precocious haddock was also significantly lower than of older fish (Alekseyeva and Tormosova, 1979; Hislop, 1988). These younger spawners have a relative potential fecundity of 274 to 300 eggs per g, compared to 393-493 eggs per $\mathrm{g}$ for older fish.

Flatfish. Feeding level significantly affects the potential fecundity of European plaice (Table 3). Plaice fed on a high ration of $2-2.3 \%$ of wet body weight per day had $60 \%$ more vitellogenic oocytes (potential fecundity) than plaice kept on a maintenance ration of $0.5-1.8 \%$ of wet body weight per day (Horwood et al., 1989). Moreover, $39 \%$ of the plaice fed with the lower ration did not produce vitellogenic oocytes. Rijnsdorp (1990) observed under experimental conditions that the main response of female plaice to a low surplus energy was to skip reproduction. The difference in potential fecundity of small fish in both rations was very limited. Since food was not allocated individually, it was concluded by the investigators that small fish in both groups could actually have acquired a similar ration, resulting in a similar potential fecundity (Horwood et $a l ., 1989)$. Fecundity estimates of plaice of the southern North Sea between 1977 and 1985 were examined for relations with growth and condition (Horwood et al., 1989; Rijnsdorp, 1991; Rijnsdorp et al., 1991). Predicted fecundity for a $40 \mathrm{~cm}$ female plaice based on fecundity-length relationships and relative fecundity (eggs per g body weight) were significantly correlated with pre-spawning condition factor $\left(r^{2}=0.67\right.$ for fecundity and pre-spawning condition). Analysis of potential fecundity with respect to length, age and somatic growth indicated that somatic growth had no effect on fecundity (Horwood et al., 1989; Rijnsdorp, 1991; Rijnsdorp et al., 1991). Somatic growth was unrelated to potential fecundity even though pre-spawning condition factor showed a weak but significant correlation with somatic growth (Rijnsdorp et al., 1991).

Similar relationships were observed for sole from the North Sea and eastern English Channel (Millner et al., 1991). Variation in potential fecundity was significantly related to length and condition factor (gutted weight/length ${ }^{3}$ ) of females at spawning while recent growth of females (growth increment) did not significantly improve the model. Body length explained about $75 \%$ of the variance in potential fecundity and the addition of condition factor to the model increased the explained variance in fecundity to $93 \%$ (Table 3 ). In contrast, recent growth rate appears to have a significant influence on potential fecundity in different stocks of sole sampled in 1991 along the European Continental Shelf from the coast of Portugal to the North Sea (Witthames et al., 1995). A positive relationship was observed between predicted fecundity at $35 \mathrm{~cm}$ ( $\mathrm{fe}-$ cundity-length relationships) and growth rate (estimated from the slope of the length-at-age growth curve).

The proportion of vitellogenic oocytes in winter flounder was related to food consumption and condition factor (Tyler and Dunn, 1976). The percentage of females producing vitellogenic oocytes increased with increasing food ration. In maturing females, the percentage of oocytes not in vitellogenesis decreased with an increase in energy consumption (kcal fish per day). The percentage of atretic oocytes was not correlated, however, with ration or any measures of condition (Table 3). It was concluded, therefore, that the decrease in the proportion of vitellogenic oocytes with the decrease in food ration was not due to atresia but to a decrease in the number of oocytes entering vitellogenesis. Field and laboratory data also indicate that a higher percentage of non-vitellogenic oocytes was associated with lower condition (Tyler and Dunn, 1976). Similar relationships were observed for both field and laboratory data. Realized fecundity of winter flounder in Narragansett Bay, Rhode Island sampled over the duration of the spawning season and spawned in captivity was shown to vary directly with female size and advancing spawning date (Buckley et al., 1991). Female size and spawning date explained $94 \%$ of the variability in realized fecundity (Table 3 ).

Potential fecundity of Greenland halibut, Reinhardtius hippoglossoides, in East-Greenland, Northeast Arctic, Flemish Cap, and Southern Grand Bank was unrelated to liver index (hepatosomatic index) and condition factor (Gunderson et al., MS 1998; Junquera et al., 1998; Roenneberg et al., MS 1998). No relationship was observed between potential fecundity and liver index for Greenland halibut in East-Greenland and Northeast Arctic. Any length effect on potential fecundity was not removed, however, before examining the effect of liver index (Gunderson et al., MS 1998; Roenneberg et al., MS 1998). Large variation in the relative potential fecundity at age (mean number of eggs per g gutted female) was observed by Junquera et al. (1998) for Greenland halibut in the Northwest Atlantic. The variations in relative fecundity were not significantly different between sampling years $(P<0.50)$. No difference in the values of mean condition factor at age were observed for the same sampling years $(P<0.50)$. It was concluded that the relative sta- 
bility in the reproductive parameters and the constancy of condition through the period analysed may indicate a resiliency of the life history traits in this species.

Herring, mackerel and anchovies. Experimental manipulation of feeding level in Atlantic herring had a significant effect on potential fecundity (Table 3 ). Adult herring on half ration had a mean potential fecundity that was $26 \%$ lower than that of fish on full ration (Ma et al., 1998). This lower potential fecundity in low-ration fish was associated with lower weights-at-lengths (i.e. lower condition). Ration had no effect on relative potential fecundity (oocytes per g). Potential and relative potential fecundity were both affected by condition in Norwegian spring-spawning herring (Kurita et al., 2000). Both Fulton's condition factor and solids condition factor (mostly protein content) had a direct relationship with potential fecundity in the months of January and February $(P<0.001)$. In Pacific herring, potential fecundity was directly related to interannual variation in winter temperature. The mean sea surface temperature 60-90 days before spawning explained $41 \%(P=0.0003)$ of the variability in potential fecundity (Tanasichuk and Ware, 1987). A similar relationship was observed for Atlantic herring in the Northwest Atlantic (Winters et al., 1993). In these two studies, interannual variation in potential fecundity appeared to be due to an inverse relationship between egg number (fecundity) and egg size. A densitydependent response to stock biomass was also observed in Atlantic herring where fecundity was inversely related to stock biomass (Winters et al., 1993). Batch fecundity in Japanese chub mackerel, Scomber japonicus, was affected by the nutritional state of the spawning females (Yamada et al., 1998). Fecundity analysis made over a limited number of females $(n=12)$ and spanning a limited size range indicated a significant correlation $(r=0.721, P<0.05)$ between batch fecundity and condition factor. No significant correlations $(P>0.05)$ were observed, however, between batch fecundity and body size (length or weight).

Variations in potential fecundity of short-lived clupeids are correlated with different factors depending on species. The relative batch fecundity of Japanese anchovy, Engraulis japonicus, was significantly related to water temperature (Funamoto and Aoki, 2002). The potential batch fecundity of anchovies, Encrasicholina devisi and E. heteroloba, from Solomon Islands, South Pacific was directly related to water temperature and zooplankton density, whereas in sprats, Spratelloides delicatulus and S. lewisi, potential batch fecundity was related to hepatosomatic index (Milton et al., 1995). Stepwise regression analysis indicated that fish weight was consistently the most significant variable affecting the potential batch fecundity of the last four species. Fish weight accounted for 24 to $71 \%$ of the variation. For the two species of anchovy, temperature and zooplankton density explained 4 to $16 \%$ of the variation in batch fecundity at the different sampling sites. Hepatosomatic index explained 3 to $34 \%$ of the variability in batch fecundity of the two sprat species at the different sites. The absence of depletion in somatic reserves during reproduction estimated by the changes in relative condition factor, liver weight, and deposits of lipid on the intestine in E. heteroloba in the same area was also interpreted as evidence that energy resources for reproduction were obtained from food intake rather than stored energy reserves (Wright, 1990). It was also suggested for the anchovy Encrasicholina punctifer from West Sumatra, Indonesia that gonadal growth (i.e. fecundity) was independent of body fat but was directly related to food intake (Maack and George, 1999).

Additional species. A very large variability in potential fecundity was observed in the orange roughy, Hoplostethus atlanticus, inhabiting the continental slope off east Tasmania. This long-lived species is found in a food-poor environment and has a low fecundity and large egg size (Koslow et al., 1995). Multiple regression analysis indicated that length, liver condition, and age all had a significant effect on potential fecundity. However, these factors explained $27 \%$ of the variance in potential fecundity. Despite this large variability in potential fecundity, significant differences in the mean relative potential fecundity were observed between years. The increase in relative fecundity over the period 1987-92 coincided with the decline in stock size. Although limited to five years of data, a significant negative correlation was observed between relative fecundity and stock size, suggesting a densitydependent effect of stock size on fecundity presumably through an increase in food availability (Koslow et al., 1995).

Similar types of relationships were observed in freshwater species. In white crappies, Pomoxis annularis, from Texas reservoirs, the percentage of mature eggs was positively correlated to relative weight $(r=0.861)$ during the pre-spawning period (Neumann and Murphy, 1992). Total lipid content was also correlated $(r=0.549)$ to the relative weight during that period. The authors concluded that relative weight could be a useful method of estimating physiological status and reproductive potential in pre-spawning white crappies. 


\section{Evaluation of observed relationships as potential proxies of fecundity}

The above cited studies demonstrate that some indicators of nutritional status of fish and the environments in which they live will be predictive of fecundity. In many cases, highly significant relationships between these parameters and fecundity were reported (Table 3). The dependency of fecundity on other biological and environmental factors that were not cited here is possible but most studies have concentrated on the factors identified in this review.

The variety of relationships between biological and environmental indices and potential or realized fecundity emphasizes that no single factor consistently excels in predicting fish fecundity. The predictive power of any factor can differ between species, stocks, and geographic areas within stocks. In long-lived species, fecundity is likely to be related to surplus energy accumulated during the feeding season while in shortlived species fecundity is often related to current food intake. Moreover, differences in the factors affecting fecundity are evident between similar species. Potential batch fecundity was correlated with zooplankton density in anchovies while potential batch fecundity was correlated to the hepatosomatic index in sprat (Milton et al., 1995). Food-limited environments will potentially lead to stronger relationships as possible strategies of allocation of energy between growth, maintenance, and reproduction will be limited. Lower species richness often observed in low-productivity ecosystems (Kassen et al., 2000) is likely to lead to stronger relationships between fecundity and different indices of nutritional status since food intake will depend on a very limited number of prey species. On the other hand, low energy costs or the absence of energy costs of egg production will decrease the dependency of fecundity on different biological and/ or environmental indices. The large variation in the nutritional condition of Atlantic cod in the Northeast Arctic (Kjesbu et al., 1998; Marshall et al., 1998) and Northern Gulf of St. Lawrence (Lambert and Dutil, 2000; Lambert et al., 2000) and the poor condition observed near the spawning period in some years could indicate that these fish are in food-limited environments in comparison to Baltic cod (Kraus et al., 2000) which show higher and less variable condition. Potential fecundity was related to different indices of fish condition in Northeast Arctic cod (i.e. liver index) and in Northern Gulf of St. Lawrence cod (i.e. condition factor) but not in Baltic cod (i.e. condition factor).
In many instances, better predictions of potential fecundity have been obtained by using more than one factor. Length and different indices of fish condition (liver index and condition factor) had significant effects on potential fecundity in cod (Kjesbu et al., 1998; Kraus et al., 2000; Lambert and Dutil, 2000; Marteinsdottir and Begg, 2002) but length explained the largest part of the variability. Although liver weight and condition factor had significant effects on fecundity of Northeast Arctic cod and Baltic cod, neither explained a substantial amount of the variability (Kjesbu et al., 1998; Kraus et al., 2000). Their inclusion in multiple regression models only increased the explained variance by $1 \%$. In Icelandic cod, however, an additional $4-13 \%$ of the variability in potential fecundity was explained by adding condition factor to the regression of fecundity on length (Marteinsdottir and Begg, 2002). In laboratory experiments, condition factor (somatic weight/length ${ }^{3}$ ) explained $23 \%$ of the variability in the fecundity of cod from the Northern Gulf of St. Lawrence (Lambert and Dutil, 2000). Differences in the range of values for length and indices of condition between studies may partially explain the differences in relative importance of each factor. For example, condition factor values (total weight/length ${ }^{3}$ ) for Baltic cod were between 1.02 and 1.22 while values (based on somatic weight) for the Gulf of St. Lawrence were between 0.7 and 1.1. Although condition factor (gutted weight/length ${ }^{3}$ ) had a significant impact on the fecundity of sole from the North Sea and Eastern English channel its effect was small as the addition of condition factor to the regression of fecundity on length increased the $r^{2}$ from 0.75 to 0.82 (Millner et al., 1991). In chub mackerel, Yamada et al. (1998) found condition factor (somatic weight/length ${ }^{3}$ ) to explain a larger proportion of the variability in batch fecundity than did length, perhaps due to the limited size range of the females in their analysis. Observed versus possible ranges of values for the different factors must be known before the interpretation of their relative roles in potential fecundity can be assessed.

The range of values considered in the development of predictive models will be important, especially if the models are developed for different stocks or for stocks inhabiting different areas. The relative importance of different factors could change with the status of a stock. For example, overfishing could reduce the size range of the spawning fish and, as a consequence, change the relative importance of length and condition factor, or any other factor, in explaining the variability in potential fecundity. 
Variations among stocks in correlates of fecundity. The reported among-stock differences in the correlations between potential/realized fecundity and selected biological and environmental factors can result from either differences in the environment where the stocks reside or differences in the sampling procedures. The timing of sampling, and methods of sampling and calculating values of fecundity and biological and environmental factors can be very different between stocks (Table 3).

Comparative studies of life history patterns in fish provide evidence of covariation in some reproductive characteristics (Elgar, 1990). Trade-off between fecundity and egg size could partly explain variations among stocks in correlates of fecundity. For example, inverse relationships between egg weight and fecundity have been observed in Atlantic herring (Hempel and Blaxter, 1967; Winters et al., 1993). However, the annual changes in fecundity were not linearly offset by reciprocal changes in egg size. On the other hand, changes in energy available for reproduction within stocks appear to be manifested primarily in the number, not the size, of eggs produced (Bailey and Almatar, 1989). Annual differences in fecundity but not in egg weight were observed in Baltic and North Sea herring (Bailey and Almatar, 1989; Laine et al., 1998).

Time of sampling of the various factors may have a considerable impact on the observed relationships with fecundity. Monthly evaluations of the relationship between condition factor and fecundity in Atlantic herring indicate that the strongest effects of condition on fecundity occur during January and February (Kurita et al., 2000). The limited effect of condition index on fecundity of North Sea and eastern English Channel sole was suggested to result from sampling the fish for condition just prior to spawning-time when condition factor (gutted weight/length ${ }^{3}$ ) would not necessarily be a reliable indicator of the state of the fish before ovary development (Millner et al., 1991). Measuring condition at the end of the growth period before the re-allocation of energy reserves to maturation was suggested as more useful (Millner et al., 1991). In such situations, however, the ovaries may not be sufficiently developed to distinguish oocytes that will be spawned and the data used to examine the relationships between fish condition or any other biological factor and fecundity will not be obtained at the individual level (i.e. measures of condition and fecundity are not obtained on the same individual). Variation in the correlations between fecundity and selected environmental or biological factors among stocks can also be generated by the use of different variables. For ex- ample, a decrease in condition due to starvation or low feeding level during maturation could increase relative fecundity through a change in body weight even though the relationship between absolute fecundity and body length remained unchanged. Thus, the use of different indices of fecundity (absolute $v s$ relative fecundity) could lead to very different results. Not removing length effects can also influence the relationships between different measures of condition and fecundity. The relationship between absolute fecundity for a large size range of fish to the condition factor (weight/length ${ }^{3}$ ) or hepatosomatic index, which are partially or completely independent of size, could mask the influence of these factors. For example, no trend was observed in the relationship between absolute fecundity and hepatosomatic index (HSI) for Greenland halibut (Roenneberg et al., MS 1998). Absolute fecundity was measured, however, on fish between 65 and $110 \mathrm{~cm}$. Thus, fish with different sizes and comparable HSI values would show very different absolute fecundities. Differences between stocks can be difficult to interpret due to the use of different definitions and formulations for the indices used as indicators of fecundity, biological and environmental factors. Standardization of the different indices is necessary before comparing stocks.

Laboratory and field data. Relationships between fish condition, growth, food intake, and fecundity have been observed in both laboratory and field situations. Laboratory experiments permit the evaluation of relationships in controlled conditions. Some validation of the relationships between the above mentioned factors and fecundity is, however, necessary before extrapolating the results of laboratory experiments to natural situations. For example, laboratory experiments with Atlantic cod demonstrated the effect of condition factor (Fulton's) on the number of previtellogenic oocytes and the fraction of these oocytes going through vitellogenesis (Kjesbu et al., 1991). The condition factors and potential fecundities of cod in the experiment were, however, much higher than those observed in wild cod cautioning the extrapolating of these results to the wild.

Direct measurements of relationships predicting realized fecundity have only been obtained from laboratory experiments. In field situations, relationships using realized fecundity have to be extrapolated from laboratory experiments or estimated from correlations that predict potential fecundity and level of atresia in the wild. Atresia is not routinely measured and few studies have examined for possible relationships between level of atresia and fish condition, growth, or 
food intake (Murua et al., 2003). Fish condition and food intake have significant though variable effects on the level of atresia observed for northern anchovy (Hunter and Macewicz, 1985), cod (Kjesbu et al., 1991; Hardardottir, MS 2001), and Atlantic herring (Ma et al., 1998; Oskarsson et al., 2002). In Atlantic herring, fish on a low ration had an average incidence of atresia twice as high as fish on high ration $(5.7 \%$ vs $3 \%)$, but this difference was not statistically significant (Ma et al., 1998).

\section{Potential use of biological and environmental factors as proxies of fecundity}

The usefulness of relationships between biological and/or environmental factors and fecundity as alternative methods of estimating egg production will depend on the capacity of the selected proxies to explain a large proportion of the variability in fecundity (high $r^{2}$ ), and on the simplicity of measurement and availability of data for these proxies. Condition factor is a good indicator of energy reserves in cod (Lambert and Dutil, 1997a, b) and general feeding level in winter flounder (Tyler and Dunn, 1976) and is potentially a good proxy of fecundity. Close relationships between different formulations of condition factor (total weight/ length ${ }^{3}$, somatic weight/length ${ }^{3}$ ) and fecundity have been observed, as well condition factor is easy to measure. Length and weight data necessary to calculate condition factor are also common in many databases. Liver index, which is also a good indicator of energy reserves, may serve as another proxy of fecundity. Though the liver index is easy to measure, historic data on liver weight are less common than those on length and weight. Moreover, at least in cod, liver index calculated from mean monthly values over one year (Marshall et al., 1998) may require a significant amount of sampling. Unless modified to reduce sampling effort to more restricted periods, the liver index may not be generally applied to several stocks of the same species. Feeding level was observed to be correlated with potential fecundity in haddock (Hislop et al., 1978) and plaice (Horwood et al., 1989). However, feeding level, which is easily controlled and measured in the laboratory, is very difficult to measure in the wild. On the other hand, prey abundance (i.e. prey availability index) which can be correlated to feeding level could potentially be easy to obtain from routine stock assessments (Kraus et al., 2002).

\section{Egg and Larval Viability}

Exploited marine fish stocks produce high numbers of viable offspring to sustain or expand their size.
In addition to number and quality of the eggs, the time and location of spawning are important because they determine the environment the eggs experience once released and fertilized. Variations in egg and larval quality are documented in aquaculture and mainly attributed to broodstock quality and environmental parameters experienced by the adults and their eggs. The number of studies that revealed similar relationships in the field is limited with the majority focused on the relationships between female size, egg size, and larval size or survival (Table 4). We summarize here the available information from field and laboratory studies covering the most important fish stocks in the NAFO and ICES areas of the North Atlantic. First, we provide a general description of the mechanisms responsible for the various inter-relationships between environmental/biological factors and offspring production. Second, we review the potential measures of survival from egg to larval stage and factors that are responsible for, interact with, or simply co-vary with egg or larval production. Third, we summarize the variety of relationships between measures of egg and larval survival and various biological and environmental factors with respect to their applicability as proxies of reproductive potential. Biotic and abiotic processes that act indirectly on survival such as predation and drift are beyond the scope of this overview and are consequently not considered.

Among the species examined, commercially important fish species such as cod, haddock, herring, capelin and several flatfish species including turbot, flounder and halibut, appeared most frequently in the literature. The influence of maternal effects on the size and quality of eggs and larvae was the most frequent type of study on biological factors affecting eggs and larvae. The majority of studies examining relationships between measures of egg and larval survival and environmental factors investigated the effects of temperature and salinity. Oxygen which is important for survival in estuarine systems was also examined. The effect of oxygen concentration on egg and larval survival has been investigated in the Baltic, where the physical environment experienced by demersal stocks like cod and flounder is characterized by low oxygen conditions (Nissling, 1994).

\section{Mechanisms affecting offspring viability}

In contrast to fecundity, the viability of eggs and larvae could be measured at successive developmental stages utilizing a variety of different viability indicators. Thus, we categorized measures of egg and larval viability into egg size, fertilization rate, egg survival/ 


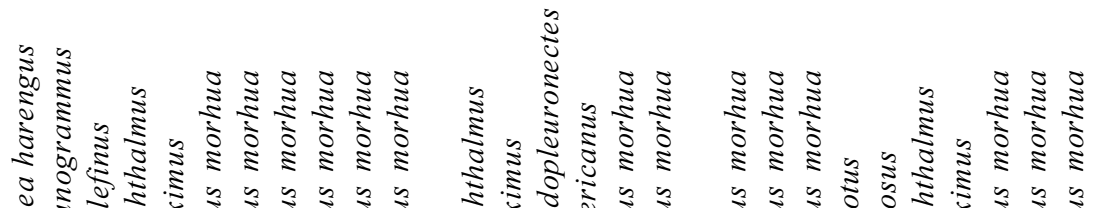

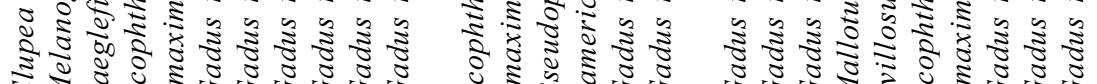
U

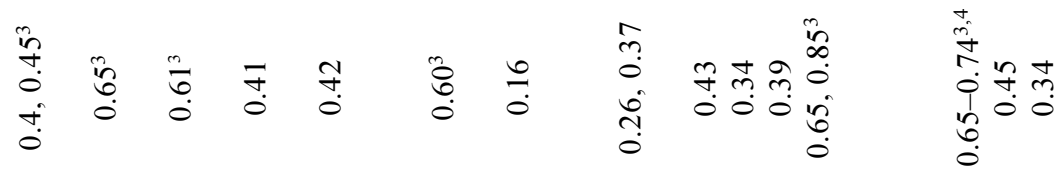

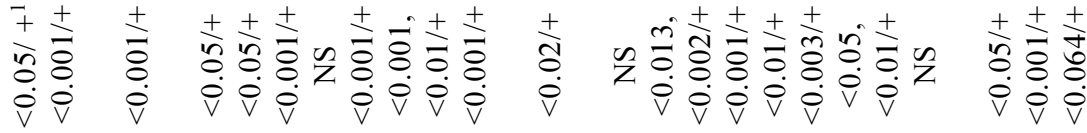
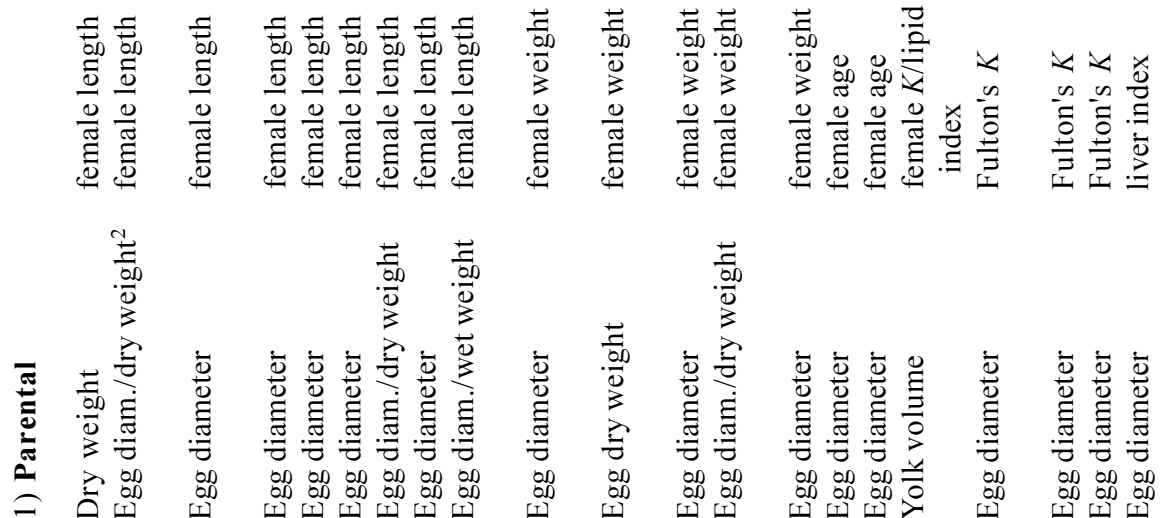


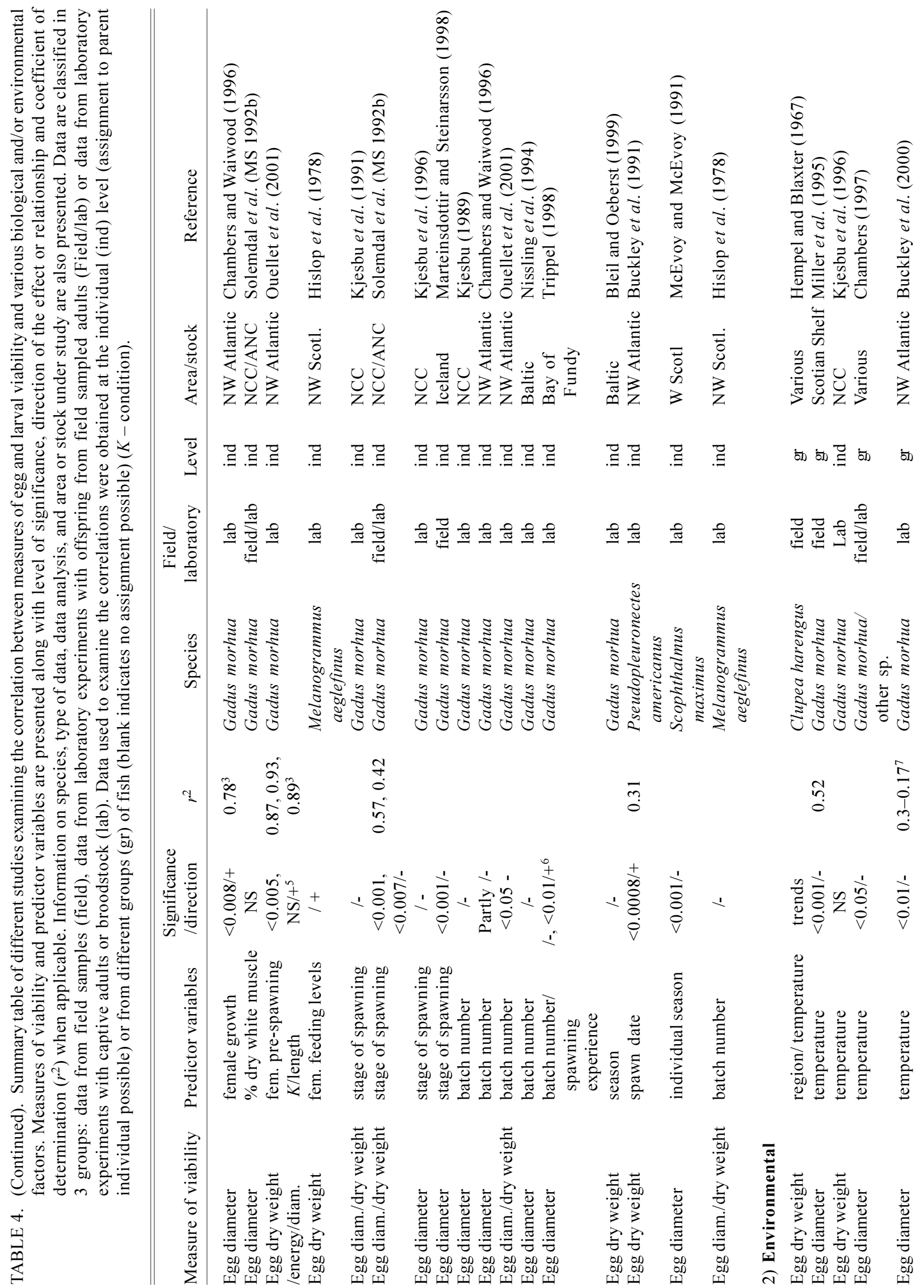




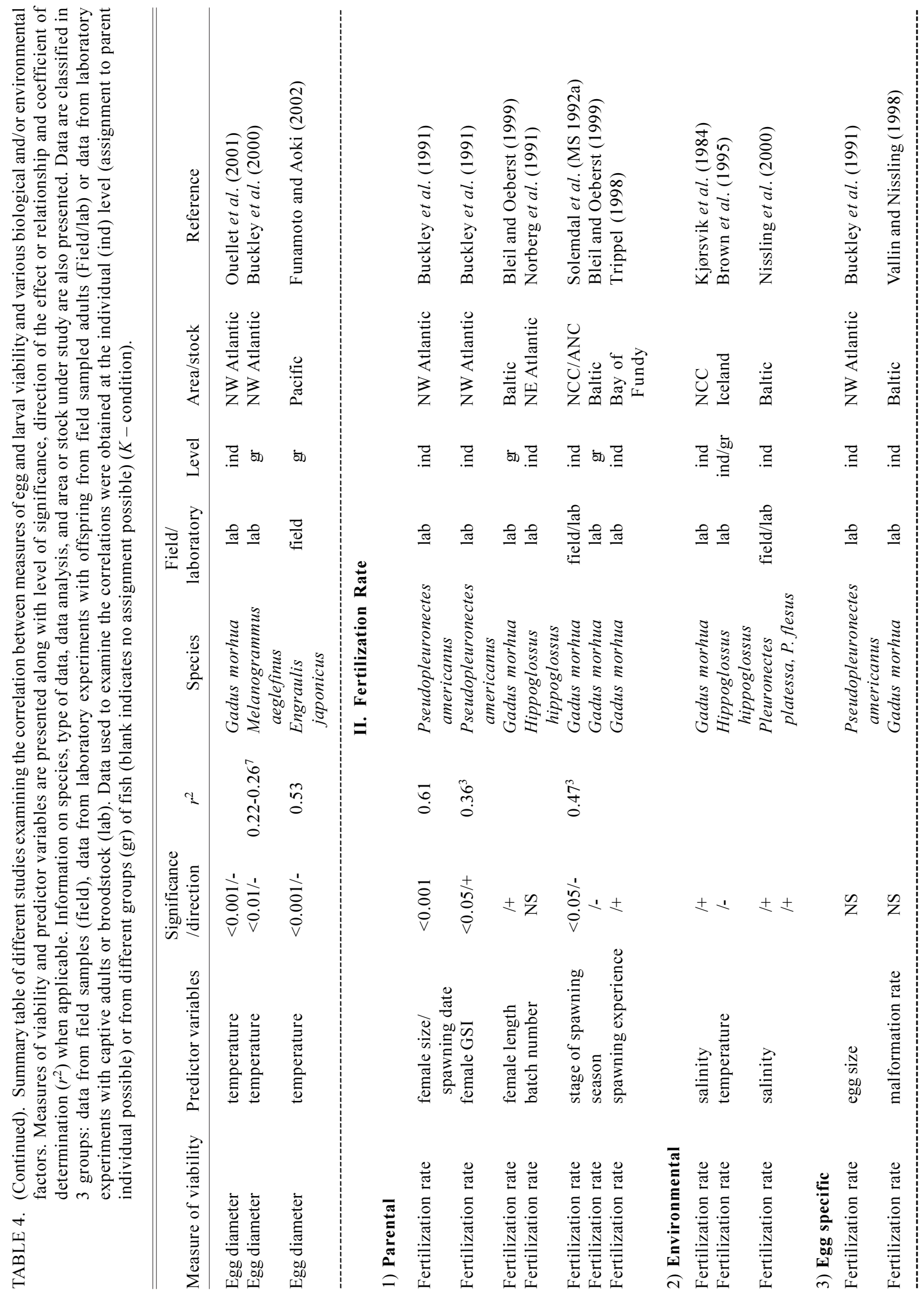


LAMBERT et al.: Environmental and Biological Indices as Proxies

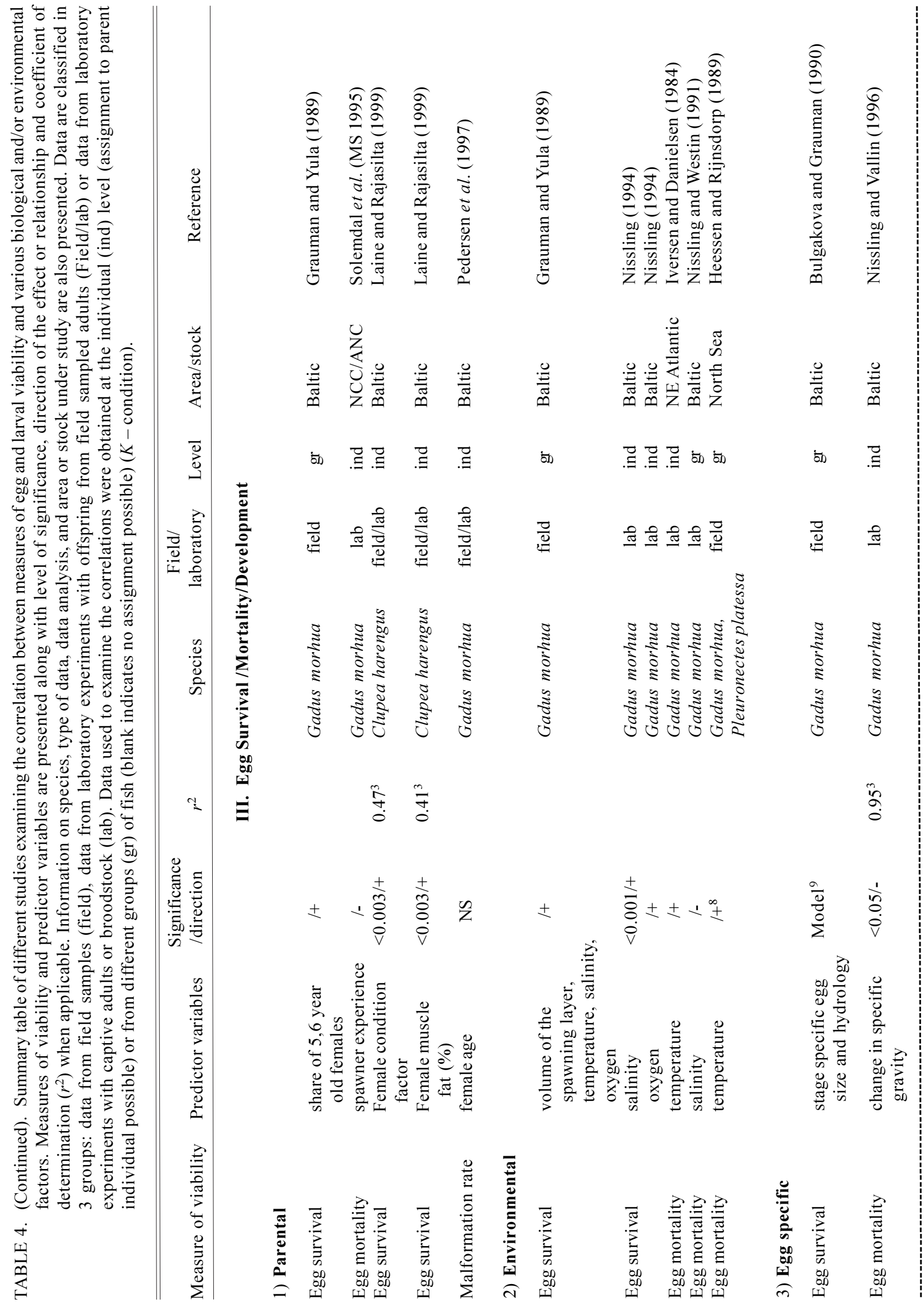


142

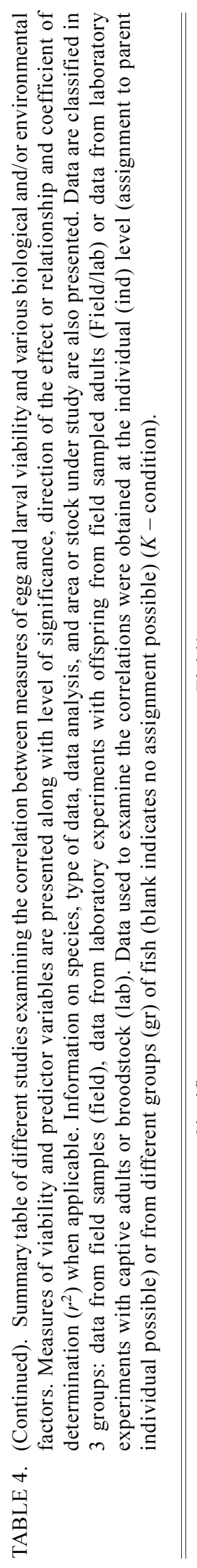

J. Northw. Atl. Fish. Sci., Vol. 33, 2003

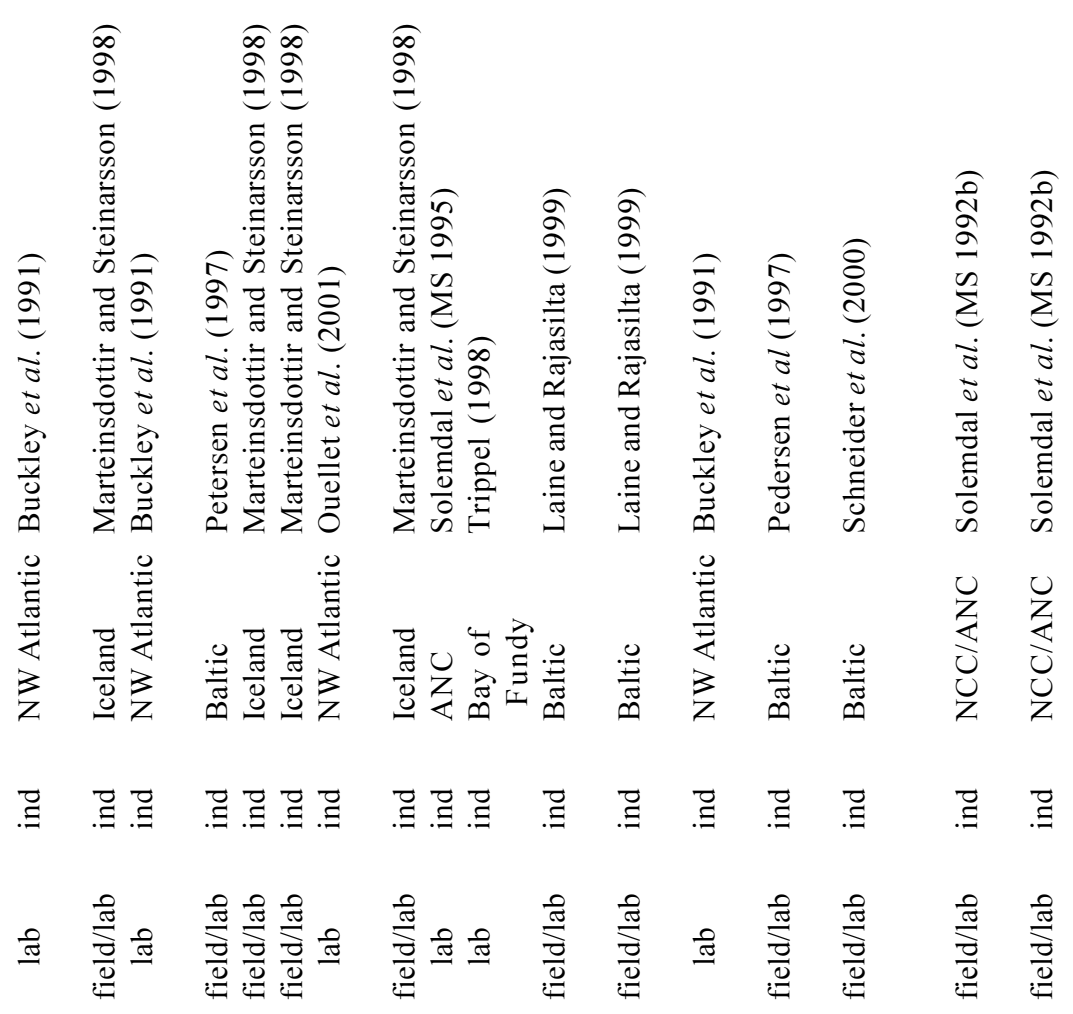

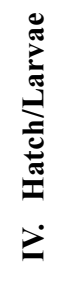

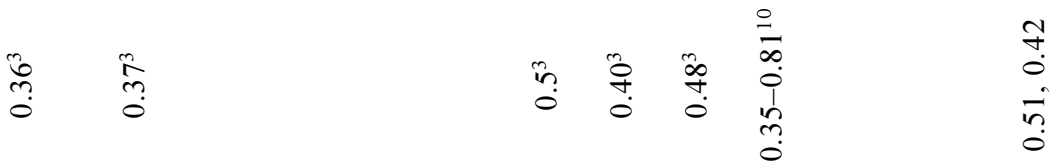

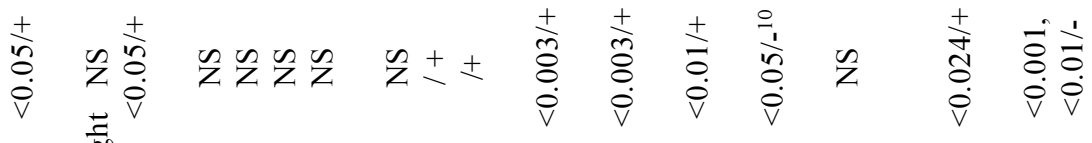

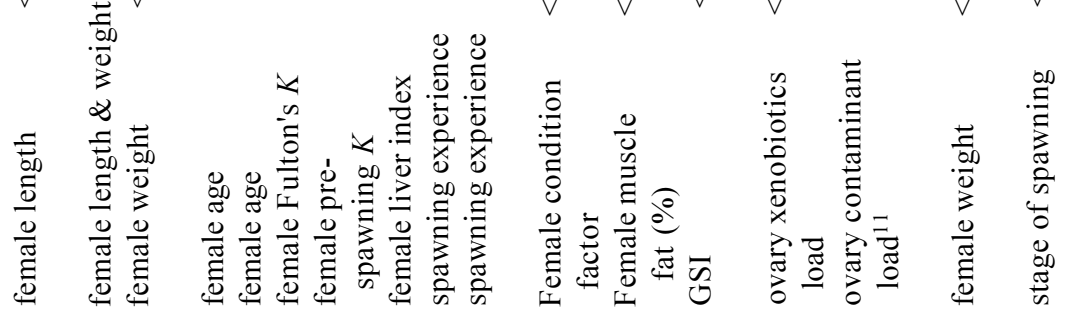

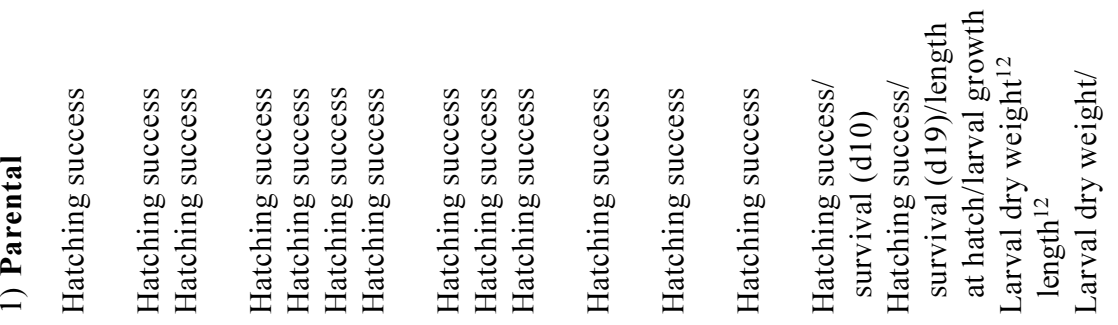




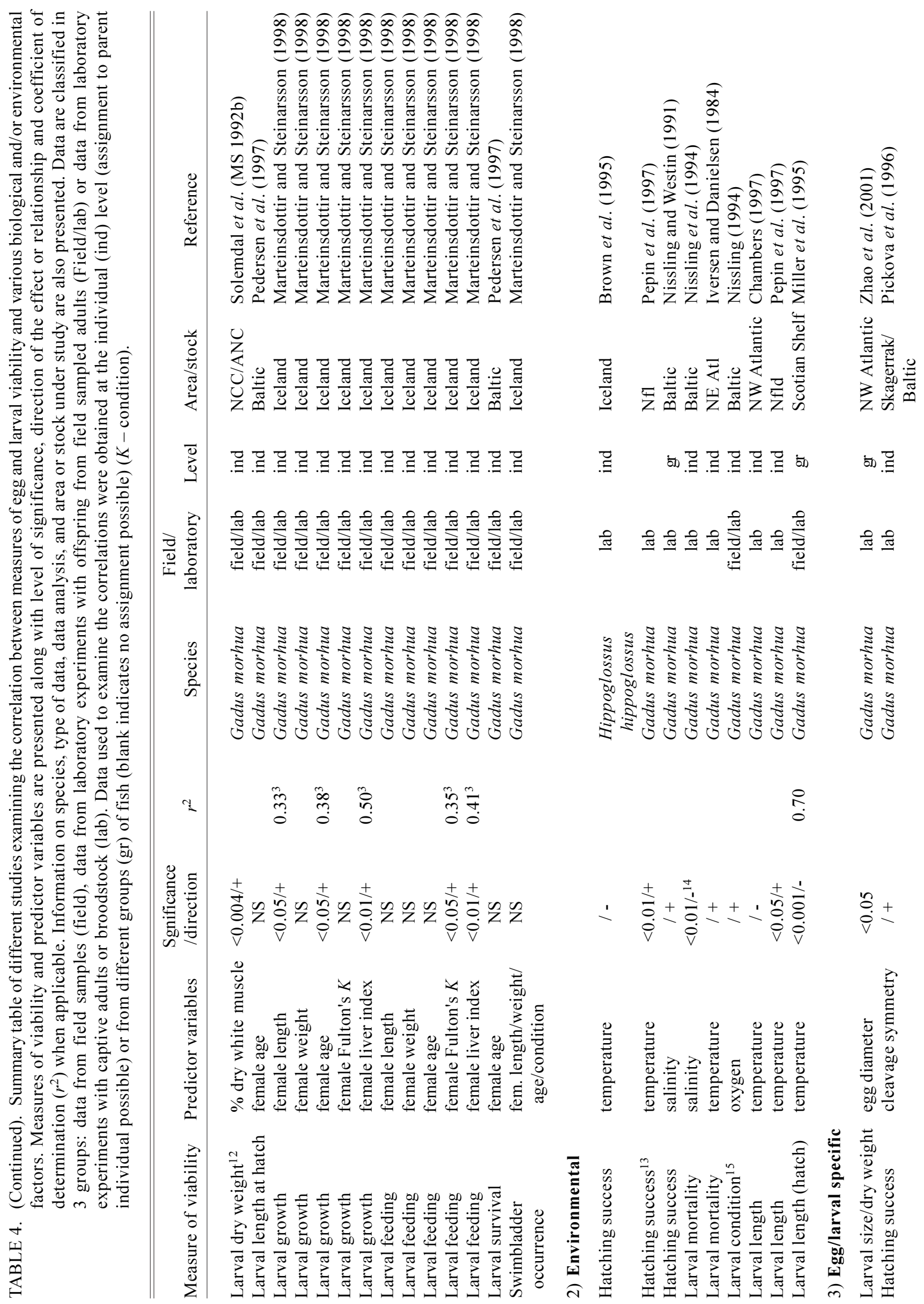




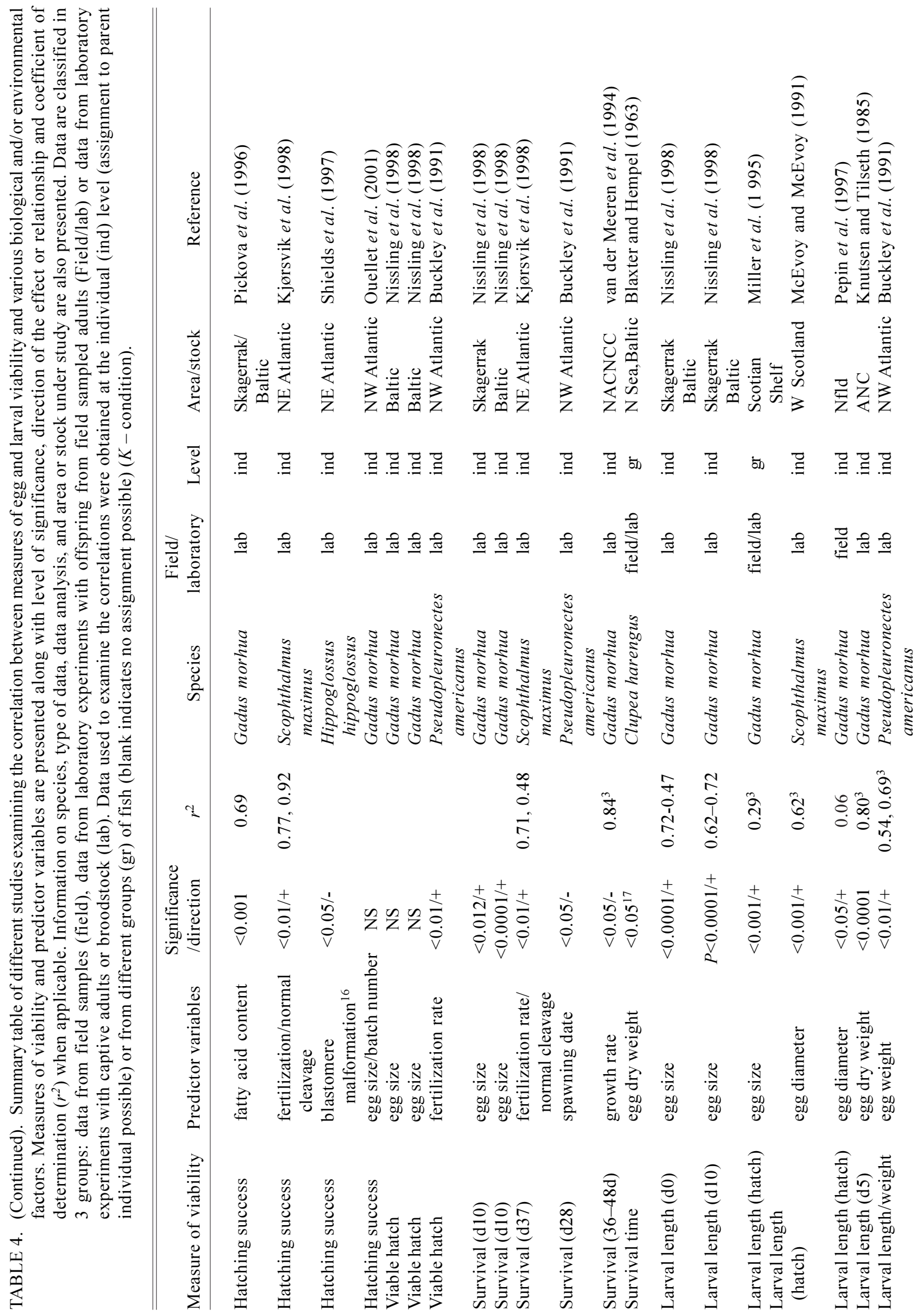




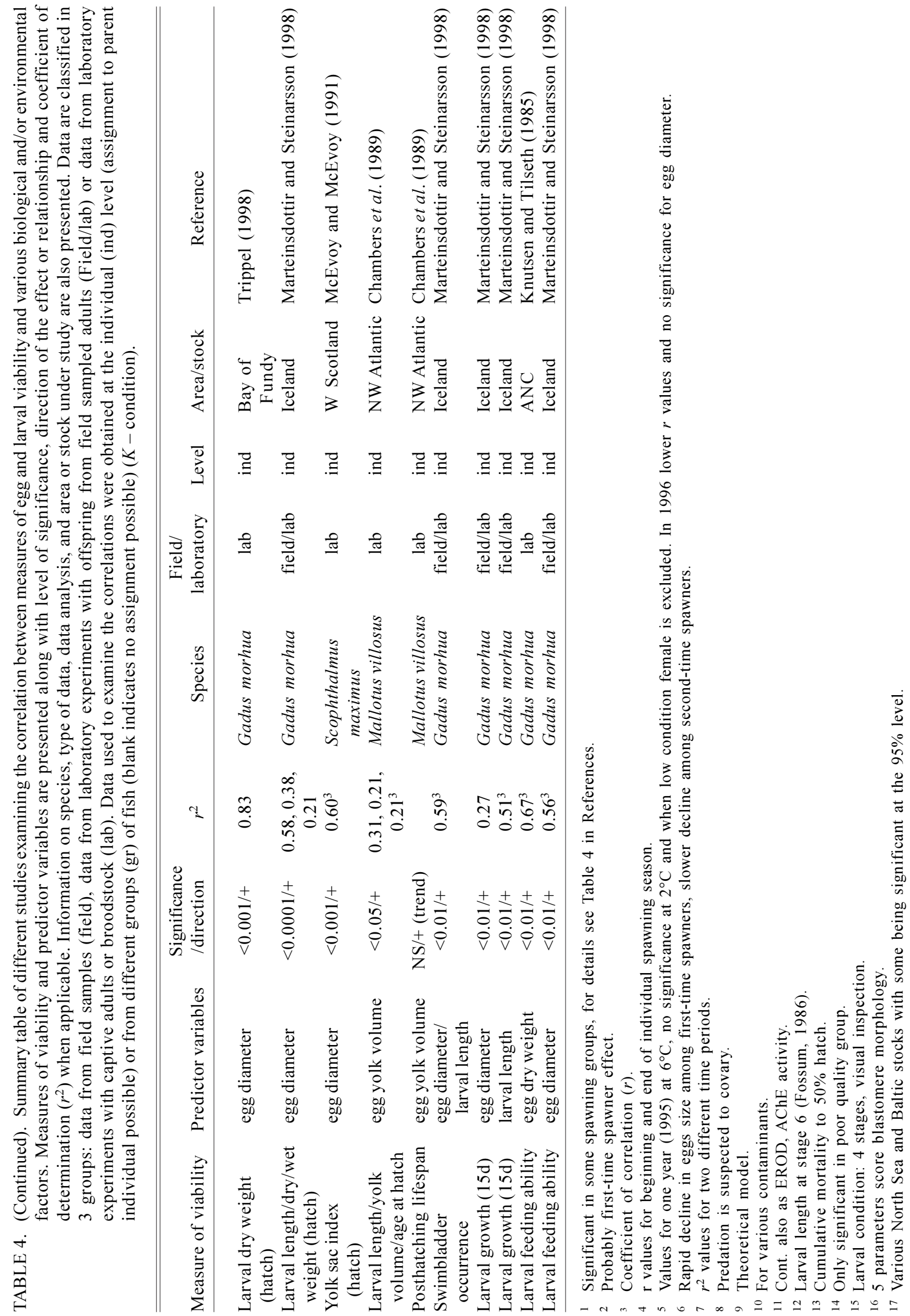


mortality, and larval characteristics. Naturally, each of these stages is influenced by various biological and environmental factors, which could differ in their strength and direction of influence between the subsequent stages. Understanding the underlying mechanisms of these inter-dependencies is essential in order to evaluate the potential of these as alternative measures of offspring viability.

The relationships between egg size and larval size as well as other viability characteristics are well documented (Table 4). Larval size, growth, and survival are positively related to egg size implying positive effects on further survival of larger larvae (e.g. via larger energy reserves), a better ability to utilize a broad food spectrum, and to avoid predators. Hence, egg size is one of the most frequently reported primary measures of egg quality and initial offspring size (Chambers, 1997). Additionally, egg size is related to parental characteristics, e.g. female age/size, spawning experience, pre-spawning condition, and environmental conditions (Table 4). However, in multiple batch-spawning species these relationships are complex, as genetic constraints and batch effects on egg size as well as seasonally changing environmental conditions can distort or mask their significance. For example, cod spawning several batches over a prolonged spawning season, show a decline in egg size from batch to batch (Chambers and Waiwood, 1996; Vallin and Nissling, 2000; Ouellet et al., 2001). In the field, this individual, seasonal decline in egg size could be confounded by the asynchronous timing and duration of spawning among individuals (Chambers and Waiwood, 1996; Marteinsdottir and Steinarsson, 1998; Tomkiewicz and Köster, MS 1999), which complicates the application of seasonal effects as proxies of egg size at the stock level.

Among environmental variables that might affect the within- and between-stock variation in egg size, temperature and salinity appear to be primary causal factors. Despite parental influences, geographical and seasonal differences in egg size can also result from the effects of changing temperature and/or salinity regimes. However, the coincidence between the seasonal decline in egg size of Atlantic mackerel with the seasonal decline in size distribution of planktonic organisms was suspected to be an adaptive mechanism to ensure an appropriate food spectrum for mackerel larvae (Ware, 1977). Whether both the decline in plankton and egg size are caused by a common factor (e.g. rising temperatures) is hard to demonstrate but a considerable amount of evidence suggests that the main effects of temperature and salinity arise during oogenesis and not at the time of spawning (Chambers, 1997). Pre-ovulated eggs are permeable to fluids, while the ovulated egg is sealed by a largely impermeable membrane. Hence, the final egg size is a product of the osmotic balance between the pre-ovulated egg and the body fluid of the female, which reflects at least to a certain degree the salinity of the habitat occupied by the female. The mechanism of the temperature effect remains difficult to explain, because a seasonal decline in egg size is often not only related to rising water temperatures (e.g. in spring-spawning species), but also to a decline in female nutritional condition as the spawning season progresses. Seasonal egg size declines occurred in captive cod held at uniform temperatures (Trippel, 1998; Ouellet et al., 2001). However, observations from egg surveys reveal an association between the size of the eggs and the ambient water temperature, an observation that is supported by broodstock data revealing also an inverse relationship between both variables (Chambers, 1997).

The number of factors and the importance of environmental influences affecting viability parameters increases when the eggs are released into the surrounding medium; e.g. the likelihood of fertilization depends on the environment, maternal predisposition, and paternal effects. Moreover, fertilization rate does not seem to be influenced by the size of eggs, but significant effects of female size and spawning stage (batch number) were revealed in a few studies (Solemdal et al., MS 1992a; Solemdal et al., MS 1992b). In contrast to the influence of female body size and age, no paternal size effects have been reported. Paternal effects include sperm density and motility (Trippel and Neilson, 1992; Nissling et al., MS 2000), which could be related to paternal condition (Rakitin et al., 1999) and water salinity (Westin and Nissling, 1991), but not to size or age of the males.

After fertilization has taken place, additional biological and environmental variables influence the probability that the egg survives and develops into a viable larva. In nature, predation mortality (Köster and Möllmann, 2000) and oxygen conditions at depth of neutral egg buoyancy (Nissling, 1994) are major environmental determinants of egg mortality with the latter being most important in stratified estuarine systems with occasionally lethal oxygen depletion e.g. the Baltic Sea. Among the parental influences on egg mortality, it seems that egg survival is related to egg size and the spawning experience of females (Solemdal et al., MS 1995), whereas no evidence was found that female 
size and condition influence survival rates. Female size may, nevertheless, affect egg mortality through its effect on egg size.

A direct influence of maternal attributes on the viability and survival of larvae is often less obvious than the effect of egg size on larval size and performance. Large, well conditioned females should theoretically produce large eggs resulting in large viable larvae. The maternal influence, nevertheless, often diminishes when investigating larval viability in relation to female characteristics, though strong relationships between size and condition of the females and egg size on the one hand, as well as between egg size and hatchling size on the other have been detected. The large number of factors and processes that could possibly affect the developing egg up until the time that larval viability is measured could distort the significance of relationships between female characteristics and larval viability parameters.

Although few investigators have shown relationships between female characteristics and offspring viability (Solemdal et al., MS 1992a; Marteinsdottir and Steinarsson, 1998), egg size could be considered an alternative measure of offspring viability because it is linked to female and larval characteristics.

\section{Correlations between biological factors, environ- mental factors, and viability indicators}

Egg size. Most of the studies examining the influence of female properties on egg size have shown that diameters or dry weights of eggs increase significantly with female length, weight, and/or age (Table 4) (Hempel and Blaxter, 1967; Hislop, 1988; Buckley et al., 1991; McEvoy and McEvoy, 1991; Solemdal et al., MS 1993; Kjesbu et al., 1996; Pedersen et al., MS 1997; Marteinsdottir and Steinarsson, 1998). In general, no large differences between length, weight, and age effects on egg size were observed. The strongest relationships between length and egg size were revealed for turbot, Scophthalmus maximus, $\left(r^{2}=0.42, P<0.001\right.$, McEvoy and McEvoy, 1991) and $\operatorname{cod}\left(r^{2}=0.42, P 0.001\right.$, Vallin and Nissling, 2000). Marteinsdottir and Steinarsson (1998) explained $43 \%$ of the variance in egg size of Icelandic cod and McEvoy and McEvoy (1991) explained $36 \%$ of the variance in egg size in turbot by female weight. Female age explained 34 and 39\% of the variance in egg size of Baltic (Pedersen et al., MS 1997) and Icelandic cod (Marteinsdottir and Steinarsson, 1998), respectively. A significant relationship between egg size and several female condition indices has been reported for $\operatorname{cod}\left(0.34<r^{2}<0.86\right)$, capelin $\left(0.42<r^{2}<0.72\right)$ and haddock (Hislop et al., 1978; Chambers et al., 1989; Chambers and Waiwood, 1996; Marteinsdottir and Steinarsson, 1998; Ouellet et al., 2001), whereas no significant relationship was revealed for turbot (McEvoy and McEvoy, 1991). At the same time, size and weight of eggs have been shown to decrease during the spawning season in cod $\left(0.42<r^{2}<0.57, P<0.05\right.$, Kjesbu and Kryvi, 1989; Kjesbu et al., 1991; Solemdal et al., MS 1992a; Kjesbu et al., 1996; Marteinsdottir and Steinarsson, 1998; Bleil and Oeberst, 1999; Ouellet et al., 2001), winter flounder $\left(r^{2}\right.$ $=0.31, P=0.0008$, Buckley et al., 1991), turbot $(P<0.001$, McEvoy and McEvoy, 1991) and haddock (Hislop et al., 1978). A distinction between factors that co-vary with versus influence egg size is needed when exploring relationships between environmental factors and egg size (Chambers, 1997). Regional differences in egg size may be due to genetic effects or differences in size structure of the parental stocks inhabiting different areas (Hempel and Blaxter, 1967). Seasonal changes in egg size may similarly result from seasonal changes in the parental stock structure, e.g. when small vs large sized spawners initiate spawning at different times (Hutchings and Myers, 1993; Marteinsdottir and Björnsson, MS 1999; Tomkiewicz and Köster, MS 1999) or from the negative relationship between female stage of spawning (batch number) and egg size resulting in a gradual decline in egg size as the season progresses. There are, however, several indications that offspring size may be influenced by physical parameters including temperature and salinity. These might in fact contribute to the underlying mechanisms of seasonal, regional, between species or between stock variations in egg size. Chambers (1997) demonstrated that among a large number of marine fish species egg size as well as larval size at hatching declined with increasing temperature (excluding extremely low temperature at which larval size decreased with decreasing temperatures). This was valid for natural populations as well as for captive fish. Miller et al. (1995) observed in ichthyoplankton surveys that cod egg and larval sizes were negatively correlated with ambient temperature ( $\left.r^{2}=0.52, P<0.001\right)$, an observation supported by the experimental works of Ouellet et al. (2001) on cod $(P<0.001)$ as well as Buckley et al. (2000) on cod $\left(0.17<r^{2}<0.3, P<0.01\right)$ and haddock $\left(0.22<r^{2}<0.26\right.$, $P<0.01)$. The mechanisms responsible for salinity induced differences in egg size have been discussed by Chambers (1997). Salinity-induced differences in egg size might explain a considerable amount of the variation between marine and estuarine stocks of the same species, but seem to play a minor role at the stock 
level, where specimens are subjected to relatively stable conditions over the ripening and spawning period. Hence, no relationships between egg size and salinity were found within stocks.

None of the reviewed studies reported trends contradicting the above general relationships between characteristics of females and eggs, though some studies did not detect statistically significant effects associated with female length (Solemdal et al., MS 1992a; Bleil and Oeberst, 1999), condition (McEvoy and McEvoy, 1991), and spawning stage (Kjesbu and Kryvi, 1989; Kjesbu et al., 1991; Nissling et al., 1994). Similarly, contradicting trends in relationships based on temperature were scarce, but Kjesbu et al. (1996) found no empirical evidence to suggest that environmental temperature regulated the observed seasonal trend in egg size and Pepin et al. (1997) found that size of Atlantic cod larvae increased with increasing temperature $(P<0.05)$. The latter observation is not necessarily contradicting the general temperature trend; reasons for the inverse temperature effect on larval size at hatching are discussed below.

Fertilization rate. Despite the fact that fertilization rate is an easily measured parameter it has not frequently been addressed by studies focusing on relationships with parental characteristics (Table 4). Maternal factors identified to influence fertilization rate are female size (Trippel, 1998; Bleil and Oeberst, 1999), stage of spawning (Solemdal et al., MS 1992b; Bleil and Oeberst, 1999) and the interaction of female size and spawning date (winter flounder: $r^{2}=0.13, P<0.05$, Buckley et al., 1991) with only the latter study giving an indication of the significance of the relationship. The correlations between female size and fertilization rate were positive, whereas female spawning state/season was either related negatively (Solemdal et al., MS 1992b) or unrelated to fertilization rate (Norberg et al., 1991). Furthermore, Buckley et al. (1991) detected a strong, positive relationship between female GSI and fertilization rate in winter flounder $\left(r^{2}=0.61, P<0.001\right)$, but found no correlation between condition indices and fertilization success. Neither female size nor stage of spawning showed consistent significance and condition was unrelated to fertilization rate. In cod, fertilization success was independent of male size (Rakitin et al., 1999). These authors as well as Trippel and Neilson (1992) concluded that there is no need to adjust spawning stock reproductive potential by the variation of sperm quality with male age/size. However, male condition had an impact on fertilization success (Rakitin et al., 1999) and further evidence exists that male stock characteristics may be more important in sub-optimal environments, e.g. low salinity in estuarine systems (STORE, 2000).

The exogenous impacts on fertilization rate were examined by testing temperature (Brown et al., 1995) and salinity (Kjørsvik et al., 1984; Nissling et al., MS 2000). In all studies considered, salinity was directly related to fertilization rates while temperature was inversely related to it. None of the reviewed studies provided probability values for the variables investigated. Relationships between temperature, salinity, and fertilization rates have most likely not been established due to the fact that the experimental studies were unable to test a sufficiently large number of temperature and salinity regimes. Nevertheless, the observed trends were consistent in all studies. Egg-specific phenotypic features like size or malformation were unrelated to fertilization. In summary, the available information on possible predictors of fertilization rate is relatively scarce and its applicability is complicated by combined male and female influences. Furthermore, the revealed relationships were often weak or nonsignificant, calling into question their utility to improve estimates of reproductive potential. For further examination of the male effect on spawning potential see Trippel (2003).

Egg survival. Cod has been studied most intensively among those species examined (Table 4). Grauman and Yula (1989) were able to show that older cod females influenced egg survival in the Central Baltic, whereas Pedersen et al. (1997) were unable to detect an age effect on the egg malformation rate in incubation experiments with Baltic cod. Solemdal (MS 1995) reported higher egg mortality for first-time spawning Norwegian coastal and Northeast Arctic cod than found in repeat spawners. Correlation analysis indicated that survival of Baltic herring eggs, as well as their hatching success, were directly related to female condition factor and female muscle fat content (Laine and Rajasilta, 1999). With respect to the environmental parameters, several relationships between egg survival and temperature, salinity, and oxygen have been reported. Temperature influences egg survival in cod (Iversen and Danielssen, 1984; Heessen and Rijinsdorp, 1989) and plaice (Heessen and Rijinsdorp, 1989), though Heesen and Rijnsdorp, whose estimates were based on egg mortality in the field, considered temperature to be of minor importance compared to predation. Salinity had a direct and significant influence on the survival of Baltic cod eggs (Nissling and Westin, 1991; Nissling, 1994). Oxygen seems to play an important role only in areas where the spawning layers are characterized by persistent oxygen depletion e.g. the 
Baltic. A positive correlation between egg mortality and decreasing oxygen content was reported from incubation experiments with Baltic cod eggs (Nissling, 1994; Wieland et al., 1994). As a consequence, there is an additional impact of egg size on survival in the Baltic. As egg size is inversely related to salinity at depth of neutral buoyancy $\left(r^{2}=0.49, P<0.001\right)$, eggs with higher buoyancy allow development in less dense and, thus, less saline water above the frequently oxygen depleted bottom water layer (Vallin and Nissling, 2000). Besides two studies on Baltic cod eggs (Bulgakova and Grauman, MS 1990; Vallin, MS 1999) we were unable to find within our review any commonly valid relationships that tried to apply egg size as a predictor of egg survival.

Viable hatch/larval survival. The size of larvae as well as other parameters associated with larval viability (hatching success, survival, feeding ability, and growth) were significantly related to egg size/weight in many species (Table 4) including cod (Knutsen and Tilseth, 1985; Miller et al., 1995; Pepin et al., 1997; Marteinsdottir and Steinarsson, 1998; Nissling et al., 1998; Trippel, 1998), turbot (McEvoy and McEvoy, 1991), capelin (Chambers et al., 1989) and winter flounder (Buckley et al., 1991). Despite the fact that many studies were able to show that large females with spawning experience produce larger eggs than did smaller females, and that larger eggs hatch into larger more viable larvae, few studies detected direct relationships between characteristics of the female and those of the larvae. Species for which significant relationships could be demonstrated were cod (Solemdal et al., MS 1992a; Marteinsdottir and Steinarsson, 1998) and winter flounder (Buckley et al., 1991), whereas both studies on cod did not detect relationships between all measures of female and larval characteristics. As an example, Marteinsdottir and Steinarsson (1998) related larval growth significantly to female length $\left(r^{2}=0.11\right.$, $P<0.05)$, age $\left(r^{2}=0.14, P<0.05\right)$ and liver condition $\left(r^{2}=\right.$ $0.25, P<0.01$ ) but not to female weight. Solemdal et al. (MS 1992b) detected significant relationships between larval dry weight and female weight $(P<0.024)$, stage of spawning $\left(r^{2}=0.51, P<0.001\right)$, and the proportion of white muscle of body weight $(P<0.004)$. In most cases, this indicates a weaker relationship between maternal and larval parameters compared to maternal egg parameters (Table 4) (Buckley et al., 1991; Marteinsdottir and Steinarsson, 1998; Trippel, 1998). In addition to egg size, early embryonic parameters like cleavage patterns or blastomere malformations were related to larval parameters. Hatch rates for cod (Pickova et al., 1997), turbot ( $r^{2}=0.92, P<0.01$, Kjørsvik et al., MS $1998)$ and Atlantic halibut $(P<0.05$, Shields et al., 1997) were directly linked to normal cleavage and blastomere formation. The use of these early embryo parameters as proxies of offspring quality is questionable due to the large effort required to measure them.

Temperature was the environmental factor most frequently investigated for effects on hatch rate and larval viability. Again, cod has been the dominant subject of research (Table 4). Temperature was reported to have a significant positive impact on hatching success and larval length at hatch (Pepin et al., 1997). The opposite trend was observed in an experimental study on hatching success of Atlantic halibut but the level of significance was not provided (Brown et al., 1995). Miller et al. (1995) also reported a significant negative effect of temperature on larval length $\left(r^{2}=0.51\right.$, $P<0.001)$. An increase in larval mortality with rising temperature was detected by Iversen and Danielsen (1984), but again an indication of the significance of the relationship was lacking. The relationships found by Pepin et al. (1997) are not necessarily contradicting the otherwise consistent relationships between larval parameters and temperature. Chambers (1997) found a dome shaped relationship between length at hatching and temperature in Atlantic cod using a broad range of temperatures including extremely low values. The temperature range used by Pepin corresponds to the lower range of conditions in Chambers' treatments. Moreover, the relationship seems to be triggered by the low standard length of the experimental group incubated at $1^{\circ} \mathrm{C}$. The above studies emphasize caution when interpreting the effect of temperature on larval quality unless the functional response has been quantified over the full temperature range that is encountered by the species of interest. The direction of the temperature impact may change depending on whether the observations are on the ascending or descending limb of a dome shaped relationship. Furthermore, the strength of the temperature effect might depend on the measure chosen, e.g. hatch rates and larval performance might be affected differently.

Salinity and oxygen effects on hatch and larval viability have been reported mainly for the Central Baltic, where the saline bottom layers are commonly oxygen depleted. A rise in cod larval mortality at low salinity $(P<0.01)$ and low oxygen conditions indicated a higher sensitivity of larvae to reduced salinity when subjected to unfavorable oxygen conditions (Nissling, 1994; Nissling et al., 1994).

\section{Evaluation of predictors of egg viability}

From our review, the most promising predictors of egg and larval quality were related to female spawning 
experience, status (Solemdal et al., MS 1992a; Solemdal et al., MS 1995), size, and condition (Marteinsdottir and Steinarsson, 1998). Strong environmentally based relationships were restricted to stocks in extreme habitats. Despite the fact that a variety of endogenous factors related to offspring viability affect more than one life stage, the impact of only a few factors could be followed through the successive developmental stages. In studies that found significant relationships between maternal parameters and measures of egg and larval viability, female size/age effects explained 11 to $14 \%$, condition between 12 and $25 \%$ and stage of spawning 42 to $51 \%$ of the variability in larval viability parameters. However, in a large number of studies significant results were not revealed at all. In his extensive review on sources of variation in egg size, Chambers (1997) reported inconsistent relationships between egg size and the age and size of females, but indicated that at least part of the inconsistencies may be attributed to confounding batch or season effects. Except for herring, where Hempel and Blaxter (1967) did not reveal significance for all stocks and years included and for cod, where in two out of eleven cases (Solemdal et al., MS 1992a; Bleil and Oeberst, 1999) no significance was found, we were able to reveal positive relationships between female size and egg size consistently among North Atlantic species covered within this review. Whether in some of the examined studies the "first-time spawner effect" (Solemdal et al., MS 1995; Kjesbu et al., 1996; Trippel, 1998; Vallin and Nissling, 2000 ) is solely responsible for the positive correlation between female and egg size, or just adds to the effect remains unclear, as in many studies no differentiation was made between first and repeat spawners. The incorporation of "first-time spawner effect" in the estimation of reproductive potential would be justified as this parameter is also an important determinant of others aspects of reproductive potential (e.g. fecundity and recruitment). The inclusion of age diversity has been shown to improve substantially the stock-recruitment relationship of Icelandic cod (Marteinsdottir and Thorarinsson, 1998). Recruitment of Eastern Baltic cod was demonstrated to be significantly influenced by the age structure of the adult stock (Cardinale and Arrhenius, 2000) and egg production of age group 5+ (Vallin and Nissling, 2000). In addition to female size and spawning experience effects, a decline in egg size over the spawning season was observed for all batch spawners. Though this decline has been observed in field studies (Ware, 1977; Miller et al., 1995) and was experimentally quantified for various fish stocks (Kjesbu et al., 1996; Trippel, 1998; Vallin and Nissling, 2000; Ouellet et al., 2001), the application in reproduc- tive potential models remains difficult as the spawning activity of large and small females is asynchronous (Kjesbu et al., 1996; Trippel et al., 1997b; Marteinsdottir and Björnsson, MS 1999; Tomkiewicz and Köster, MS 1999) and the timing of the spawning season may not be constant over years (Wieland et al., 2000).

In several cod stocks, female condition affects offspring viability and explains up to $80 \%$ of the variance in egg size. The influence of the maternal liver index and condition factor on larval feeding and growth has only been reported for Icelandic cod (Marteinsdottir and Steinarsson, 1998). It seems that the effect of condition on viability plays an important role in stocks exposed to temporal shortages in food supply. For example in Eastern Baltic cod, which experience abundant prey (e.g. sprat stocks are at the highest level on record, ICES, MS 1999), no impact of female condition on size and buoyancy of eggs was observed (Vallin and Nissling, 2000). In contrast, significant relationships have been found in Icelandic and Northwest Atlantic cod stocks (Chambers and Waiwood, 1996; Marteinsdottir and Steinarsson, 1998; Marteinsdottir and Begg, 2002). Apparently, the impact of female condition is weaker than the seasonal effect and regulates fecundity rather than offspring quality (Kjesbu et al., 1998; Marshall et al., 1998; Lambert and Dutil, 2000). Female condition indices appear to be the most promising proxies for the number of eggs produced per female, but they also may be predictive of the quality of eggs produced. When considering the paternal influence, information is generally scarce. Male condition has been shown to affect fertilization success (Rakitin et al., 1999) and further evidence exists, that male characteristics become important under sub-optimal conditions in for example estuarine systems (STORE, 2000), but these findings are far from being applicable in prediction models in the foreseeable future.

The endogenous factors discussed above are related to parental phenotype and are, therefore, likely to change with the size/age and condition composition of the spawning population (Solemdal, 1997), which have been shown to affect stock-recruitment relationships (Marshall et al., 1998; Marteinsdottir and Thorarinsson, 1998). Additionally, several exogenous factors have been identified that act independently of stock structure, but affect egg and larval production during oogenesis or after the eggs are released. Among these are temperature, salinity and oxygen. For estuaries, which are characterized by a persistent stratification 
of water masses, oxygen depletion, and low salinity have proven to be of additional importance for viability parameters. The effects of temperature on egg and larval size are documented and reviewed by Chambers (1997). Egg size and size at hatch generally decrease with increasing water temperatures in both marine and freshwater species. The interpretation of these results is somewhat complex, as temperature might not equally affect the sequential processes of ontogeny (Chambers, 1997). However, the sum of the underlying processes seems to result in consistently higher hatch rates (Brown et al., 1995; Buckley et al., 2000), larger larvae (Miller et al., 1995; Chambers, 1997) and reduced mortality (Iversen and Danielssen, 1984) at cooler temperatures. Potential problems in these relationships may arise under extreme conditions as very low temperatures result in small sizes at hatching (Chambers, 1997; Pepin et al., 1997) and decreased hatch rates (Buckley et al., 2000). The dominant pattern of increased size of eggs and larvae at cooler temperatures makes water temperature a candidate to be incorporated in models of reproductive potential. Nevertheless, its implementation as a proxy of reproductive potential remains difficult due to the fact that temperatures are largely unpredictable. Furthermore, differences in timing of spawning and maternal seasonal effects may amplify or counter the effects due to temperature (Kjesbu et al., 1992).

Effects of salinity on egg size of marine fish are rarely reported (Nissling and Westin, 1997). Low salinity, common to estuarine systems, appears to affect fertilization success (Solemdal, MS 1970; Kjørsvik et al., 1984; Westin and Nissling, 1991; Nissling et al., MS 2000) as well as egg and larval survival (Nissling, 1994; Nissling et al., 1994). Oxygen as a limiting factor of reproductive success appears to play an important role only in extreme environments such as estuaries, where development of fish eggs is restricted to saline bottom water that is subjected to seasonal depletion of oxygen reserves. For cod of the Eastern Baltic, oxygen, salinity and temperature have been identified to be key variables responsible for successful reproduction and led to the definition of the threshold values of reproductive volume (Plikshs et al., MS 1993; MacKenzie et al., 2000), i.e. a water volume characterized by minimum requirements for egg survival (salinity $11 \mathrm{psu} ; 2 \mathrm{ml} / 1$ oxygen concentration and $1.5^{\circ} \mathrm{C}$ ). The definition of such threshold levels appears to be a means of accounting for environmental variables whose actions are not fully understood or those variables that affect different ontogenetic levels at different rates. This method has already been applied in stock-recruitment models of Eastern Baltic cod (Köster et al., 2003).

\section{Summary}

This review demonstrates that with our present knowledge, alternative methods of measurement could potentially be developed for some of the reproductive characteristics needed to estimate egg and larval production. Relationships between biological and environmental factors and sex-specific maturity at size or age, fecundity, egg viability, and/or larval hatching success demonstrate the large variability in these reproductive parameters and the capacity of some biological/environmental indices to explain a substantial amout of this variabiliy. This emphasizes the importance of monitoring on a routine basis the reproductive characteristics of fish stocks in order to obtain accurate measurements of stock reproductive potential (Tomkiewicz et al., 2003). In that context, the use of relationships between biological/environmental indices and reproductive characteristics as predictors of maturation, fecundity, and egg/larval viability provide a means of estimating reproductive potential in the absence of data for some reproductive characteristics, in situations where routine monitoring of these parameters is impossible or to simplify the measurement of reproductive characteristics.

Fecundity is probably the best candidate variable that could be estimated by indirect methods. These indirect methods include the relationships between indices of nutritional condition (condition factor, liver index) and potential fecundity. Some of the indices satisfy the important criteria for surrogates of predictability and simplicity. Significant correlations were observed between various maternal attributes, egg and larval characteristics, and egg and larval viability. Unfortunately, these associations could rarely be followed through successive developmental stages. The relationships between female spawning status (first time $v s$ repeat spawner) and the size and survival of eggs and larvae are probably the most promising proxies for egg and larval viability. The concept of reproductive volume may represent a means to incorporate environmentally based proxies into egg production models. At this time it appears that qualitative information about egg and larval survival could be obtained from evaluating female spawning status in populations.

Considerable fluctuations exist in maturation and age- and size-at-maturity. Suitable proxies for age- and size-at-maturity have yet to be identified. Growth and condition of adults, population density (i.e. spawning biomass), and temperature effects are among the list of potential proxies for age- and size-at-maturity, but the proportion of variability in age/size-at-maturity ex- 
plained by these variables is low. Given our present knowledge, an adequate proxy for age/size-at-maturity does not exist.

Important criteria to consider for the use of relationships between biological/environmental indices and reproductive characteristics as indirect measures of age/size-at-maturity, fecundity, and egg/larval viability include the capacity of these indirect measures to explain a large proportion of the variability in the reproductive parameters, the simplicity of measurement of these indirect measures, and their possible scale of application. Before advocating the use of surrogate measures of a stock's reproductive potential, a careful examination of the predictive power of indirect measures is needed. Models explaining $>65 \%$ of the variance and having narrow confidence intervals and steep slopes $(b)$ will yield greater predictive power (Prairie, 1996; McEdward and Morgan, 2001). Some form of validation will also be necessary in order to determine the appropriate level of generality of the relationships used as proxies. Some relationships may be stock specific while others may be applicable to several stocks.

The correlations between reproductive characteristics and environmental and biological indices can be an interesting tool to hindcast and predict egg/larval production and viability in fish stocks. This information could also be used to explain variability in relationships between spawning biomass, egg/larval production, and recruitment. We suggest that case studies using different populations of the same species could be used as a method of validation of these alternative approaches. Laboratory studies that examine relationships between biological and environmental indices and realized fecundity, level of atresia, egg/larval characteristics and viability could further improve our capacity to estimate reproductive potential. These studies once validated, could be extrapolated to field situations.

There is increasing evidence that potential egg production is superior to spawning stock biomass as a measure of the reproductive potential of a stock (Marshall et al., 1998; Marshall et al., 1999; Kraus et al., 2002; Marshall et al., 2003). Accurate estimation of reproductive potential will require a close monitoring of sex ratio, age/size-at-maturity, fecundity, and egg survival. In the absence of regular information on these reproductive parameters, indirect measures of these parameters based on relationships between biological and environmental factors and reproductive characteristics would be most valuable.

\section{Acknowledgements}

We greatly appreciate the comments and suggestions made by two anonymous referees that led to improvement of an earlier manuscript draft.

\section{References}

ADAMS, S. M. 1998. Ecological role of lipids in the health and success of fish populations. In: Lipids in freshwater ecosystems. M.T. Arts, and B.C. Wainman. (eds.). Springer, p. 132-160.

AJIAD, A., T. JAKOBSEN, and O. NAKKEN. MS 1998. Sexual difference in maturation of Northwest Arctic cod. NAFO SCR. Doc., No. 103, Serial No. N4004, $24 \mathrm{p}$.

ALEKSEYEVA, Y. I., and I. D. TORMOSOVA. 1979. Maturation, spawning and fecundity of the North Sea haddock, Melanogrammus aeglefinus. J. Ichthyol., 19: $56-64$.

ALEXEYEV, F. E., and E. I. ALEXEYEVA. 1998. Spatial differentiation and maturation rate of cod in the SouthEastern Baltic Sea. In: Proceedings on fisheries biological research by Atlant. NIRO in the Baltic Sea during 19961997. p. 36-44 (in Russian).

ALM, G. 1959. Connections between maturity, size and age in fishes. Rep. Inst. Fresh. Res., 40: 5-145.

ALTUKHOV, Y. P. 1994. Genetic consequences of selective fishing. Genetics, 30: 5-21 (in Russian).

1998. Allozyme heterozygosity, sexual maturation rate and longevity. Genetics, 34: 908-919 (in Russian).

ALTUKHOV, Y. P., and E. A. SALMENKOVA. 1991. The genetic structure of salmon populations. Aquaculture, 98: $11-40$.

ALTUKHOV, Y. P., and N. V. VARNAVSKAYA. 1983. Adaptive genetic structure and its connection with intrapopulation differentiation for sex, age and growth rate in sockeye salmon, Oncorhynchus nerka (Walbaum). J. Genetics, 19: 796-807 (in Russian).

BAILEY, R. S., and S. M. ALMATAR. 1989. Variation in the fecundity and egg weight of herring (Clupea harengus L.). Part 2. Implications for hypotheses on the stability of marine fish populations. ICES J. Cons., 45: $125-130$.

BALON, E. K. 1984. Patterns in the evolution of reproductive styles in fishes. In: Fish reproduction: strategies and tactics. G. W. Potts and R. J. Wootton (eds.). Academic Press, London, UK, p. 35-53.

BEACHAM, T. D. 1983. Variability in median size and age at sexual maturity of Atlantic cod, Gadus morhua, on the Scotian Shelf in the northwest Atlantic Ocean. Fish. Bull. U.S., 81: 303-321.

BLACKWELL, B. G., M. L. BROWN, and D. W. WILLIS. 2000. Relative weight (Wr) status and current use in fisheries assessment and management. Rev. Fish. Sci., 8: $1-44$.

BLEIL, M., and R. OEBERST. 1999. Spawning of cod in captivity. Part 2: Egg quality and rate of fertilisation of Baltic cod. Inf. Fischwirtsch. Fischereiforsch., 46: 10-16. 
BOLGER, T., and P. L. CONNOLLY. 1989. The selection of suitable indices for the measurement and analysis of fish condition. J. Fish. Biol., 34: 171-182.

BORISOV, V. M. 1978. The selective effect of fishing on the population structure of species with a long life cycle. J. Ichthyol., 18: 896-904 (in Russian).

BRAATEN, B. 1984. Growth of cod in relation to fish size and ration level. In: The propagation of cod Gadus morhua L. an international symposium. E. Dahl, D. S. Danielssen, E. Moksness, and P. Solemdal (eds.). Floedevigen Rapp., Arendal (Norway). p. 677-710.

BRANDER, K. M. 1994. Patterns of distribution, spawning, and growth in North Atlantic cod: The utility of interregional comparisons. ICES Mar. Sci. Symp., 198: 406-413.

BROWN, N. P., N. R. BROMAGE, and R. J. SHIELDS. 1995. The effect of spawning temperature on egg viability in the Atlantic halibut, (Hippoglossus hippoglossus). In: Proceedings of the 5th international symposium on the reproductive physiology of fish. F. W. Goetz and P. Thomas (eds.). Fish Symp. 95, Austin, Texas, USA, p. 181.

BRULE, T. 1987. The reproductive biology and the pathological changes of the plaice Pleuronectes platessa (L.) after the Amoco Cadiz oil spill along the northwest coast of Brittany. J. Mar. Biol. Assoc. U.K., 67: 237-247.

BUCKLEY, L. J., T. M. BRADLEY, and J. ALLENGUILMETTE. 2000. Production, quality, and low temperature incubation of eggs of Atlantic cod Gadus morhua and haddock Melanogrammus aeglefinus in captivity. J. World Aquacult. Soc., 31: 22-29.

BUCKLEY, L. J., A. S. SMIGIELSKI, T. A. HALAVIK, E. M. CALDARONE, B. R. BURNS, and G. C. LAURENCE. 1991. Winter flounder Pseudopleuronectes americanus reproductive success. II. Effects of spawning time and female size on size, composition and viability of eggs and larvae. Mar. Ecol. Prog. Ser., 74: 125-135.

BULGAKOVA, T. I., and G. B. GRAUMAN. MS 1990. A model of embryonic period of development in Baltic Sea cod. ICES C.M. Doc., No. 1990/J:10, 21 p.

BURTON, M. P. M. 1991. Induction and reversal of the non-reproductive state in winter flounder, Pseudopleuronectes americanus Walbaum, by manipulating food availability. J. Fish. Biol., 39: 909-910.

1994. A critical period for nutritional control of early gametogenesis in female winter flounder, Pleuronectes americanus (Pisces: Teleostei). J. Zool., 233: 405-415.

BURTON, M. P. M., R. M. A. PENNEY, and S. BIDDISCOMBE. 1997. Time course of gametogenesis in Northwest Atlantic cod (Gadus morhua). Can. J. Fish. Aquat. Sci., 54(Suppl. 1): 122-131.

CARDINALE, M., and F. ARRHENIUS. 2000. The influence of stock structure and environmental conditions on the recruitment process of Baltic cod estimated using a generalized additive model. Can. J. Fish. Aquat. Sci., 57: 2402-2409.
CARDINALE, M., and J. MODIN. 1999. Changes in sizeat-maturity of Baltic cod (Gadus morhua) during a period of large variations in stock size and environmental conditions. Fish. Res., 41: 285-295.

CHAMBERS, R. C. 1997. Environmental influences on egg and propagule sizes in marine fishes. In: Early life history and recruitment in fish populations. R. C. Chambers and E. A. Trippel (eds). Chapman and Hall, New York, p. 63-102.

CHAMBERS, R. C., W. C. LEGGETT, and J. A. BROWN. 1989. Egg size, female effects, and the correlations between early life history traits of capelin, Mallotus villosus : An appraisal at the individual level. Fish. Bull. U.S., 87: 515-523.

CHAMBERS, R. C., and K. G. WAIWOOD. 1996. Maternal and seasonal differences in egg sizes and spawning characteristics of captive Atlantic cod, Gadus morhua. Can. J. Fish. Aquat. Sci., 53: 1986-2003.

CHEN, Y., and L. G. S. MELLO. 1999. Growth and maturation of cod (Gadus morhua) of different year classes in the Northwest Atlantic, NAFO subdivision 3Ps. Fish. Res., 42: 87-101.

DAHLE, R., G. L. TARANGER, and B. NORBERG. 2000. Sexual maturation and growth of Atlantic cod (Gadus morhua L.) reared at different light intensities. In: Proceedings of the 6th international symposium on the reproductive physiology of fish. B. Norberg, O. S. Kjesbu, G. L. Taranger, E. Andersson, and S. O. Stefansson (eds.). University of Bergen, Bergen, Norway, p. 336.

DENIEL, C. 1984. Relations between sexual activity and growth in flatfishes from Douarnenez bay. Cybium (3e Ser.), 8: 83-93.

EINUM, S., and I. A. FLEMING. 2000. Highly fecund mothers sacrifice offspring survival to maximize fitness. Nature, 405: 565-567.

ELGAR, M. A. 1990. Evolutionary compromise between a few large and many small eggs: Comparative evidence in teleost fish. Oikos, 59: 283-285.

ELIASSEN, J. E., and O. VAHL. 1982. Seasonal variations in biochemical composition and energy content of liver, gonad and muscle of mature and immature cod, Gadus morhua (L.) from Balsfjorden, northern Norway. J. Fish Biol., 20: 707-716.

FOSSUM, P. 1986. A staging system for larval cod (Gadus morhua L.). Fiskeridir. Skr. (Havunders) 18: 69-76.

FUNAMOTO, T., and I. AOKI. 2002. Reproductive ecology of Japanese anchovy off the Pacific coast of eastern Honshu, Japan. J. Fish. Biol., 60: 154-169.

GADGIL, M., and W. H. BOSSERT. 1970. Life historical consequences of natural selection. Am. Nat., 104: 1-24.

GEODAKIAN, V. A. 1974. Differential mortality and reaction norm of males and females. Ontogenetic and phylogenetic plasticity. J. Gen. Biol., 35: 376-385 (in Russian).

1981. Sexual dimorphism and "paternal effect". J. Gen. Biol., 42: 657-668 (in Russian).

GLEBOV, T. I. 1963. Cod on the Murmansk coast. Trudy PINRO, 15: 69-130. (in Russian). 
GODØ, O. R., and T. HAUG. MS 1998. Growth rate and sexual maturity in cod (Gadua morhua) and Atlantic halibut (Hippoglossus hippoglossus). NAFO SCR Doc., No. 110, Serial No. N4011, 15 p.

1999. Growth rate and sexual maturity in cod (Gadus morhua) and Atlantic halibut (Hippoglossus hippoglossus). J. Northw. Atl. Fish. Sci., 25: 115-123.

GODØ, O. R., and E. MOKSNESS. 1987. Growth and maturation of Norwegian coastal cod and Northeast Arctic cod under different conditions. Fish. Res., 5: 235-242.

GRAUMAN, G. B., and E. YULA. 1989. The importance of abiotic and biotic factors in the early ontogenesis of cod and sprat. ICES Rapp. Proc.-Verb., 190: 207-210.

GUNDERSON, A. C., O. S. KJESBU, A. STENE, and K. H. NEDREAAS. MS 1998. Fecundity of Northeast Arctic Greenland halibut (Reinhardtius hippoglossoides). NAFO SCR Doc., No. 107, Serial No. N4008, 9 p.

HANSEN, T., O. S. KJESBU, J. C. HOLM, and O. KARLSEN. 1995. Growth, gonadal development and spawning time of Atlantic cod (Gadus morhua) reared under different photoperiods. In: Proceedings of the 5 th international symposium on the reproductive physiology of fish. F. W. Goetz and P. Thomas (eds.). Fish Symp. 95, Austin, Texas. p. 186.

HARDARDOTTIR, K. MS 2001. Atresia in Icelandic cod (Gadus morhua L.) prior to and during spawning. Thesis for Cand. Scien. degree, Department of Fisheries and Marine Biology, University of Bergen, December 2001, $52 \mathrm{p}$.

HAUG, T., and J. TJEMSLAND. 1986. Changes in sizeand age-distributions and age at sexual maturity in Atlantic halibut, Hippoglossus hippoglossus, caught in North Norwegian waters. Fish. Res., 4: 145-155.

HEESSEN, H. J. L., and A. D. RIJNSDORP. 1989. Investigations on egg production and mortality of cod (Gadus morhua L.) and plaice (Pleuronectes platessa L.) in the southern and eastern North Sea in 1987 and 1988. ICES Rapp. Proc.-Verb., 191: 15-20.

HEMPEL, G., and J. H. S. BLAXTER. 1967. Egg weight in Atlantic herring (Clupea harengus L.). J. Cons. Int. Explor. Mer, 31: 170-195.

HENDERSON, B. A., J. L. WONG, and S. J. NEPSZY. 1996. Reproduction of walleye in Lake Erie: Allocation of energy. Can. J. Fish. Aquat. Sci., 53: 127-133.

HISLOP, J. R. G. 1988. The influence of maternal length and age on the size and weight of the eggs and the relative fecundity of the haddock, Melanogrammus aeglefinus, in British waters. J. Fish. Biol., 32: 923-930.

HISLOP, J. R. G., A. P. ROBB, and J. A. GAULD. 1978. Observations on effects of feeding level on growth and reproduction in haddock, Melanogrammus aeglefinus (L.) in captivity. J. Fish. Biol., 13: 85-98.

HISLOP, J. R. G., and A. M. SHANKS. 1981. Recent investigations on the reproductive biology of the haddock, Melanogrammus aeglefinus, of the northern North Sea and the effects on fecundity of infection with the copepod parasite Lernaeocera branchialis. ICES J. Cons., 39: 244-251.

HORWOOD, J. W., M. GREER WALKER, and P. WITT-
HAMES. 1989. The effect of feeding levels on the fecundity of plaice (Pleuronectes platessa). J. Mar. Biol. Assoc. U.K., 69: 81-92.

HUNT, J. J. 1996. Rates of sexual maturation of Atlantic cod in NAFO Division 5Ze and commercial fishery implications. J. Northw. Atl. Fish. Sci., 18: 61-75.

HUNTER, J. R., and B. J. MACEWICZ. 1985. Rates of atresia in the ovary of captive and wild northern anchovy, Engraulis mordax. Fish. Bull. U.S., 83: 119-136.

HUTCHINGS, J. A., and R. A. MYERS. 1993. Effect of age on the seasonality of maturation and spawning of Atlantic cod, Gadus morhua, in the Northwest Atlantic. Can. J. Fish. Aquat. Sci., 50: 2468-2474.

ICES. MS 1999. Report of the Baltic Fisheries Assessment Working Group. ICES C.M. Doc., No. 1999/ACFM:15, $296 \mathrm{p}$

IVERSEN, S. A., and D. S. DANIELSSEN. 1984. Development and mortality of cod (Gadus morhua L.) eggs and larvae in different temperatures. In: The propagation of cod Gadus morhua an international symposium. L. E. Dahl, D.S. Danielssen, E. Moksness, and P. Solemdal (eds.). Floedevigen Rapp., Arendal (Norway), Vol. 1, p. 49-65.

JENNINGS, S., M. J. KAISER, and J. D. REYNOLDS. 2001. Marine fishery ecology. Blackwell Science, Oxford. $432 \mathrm{p}$.

JOBLING, M. 1982. Food and growth relationships of the cod, Gadus morhua L., with special reference to Balsfjorden, north Norway. J. Fish Biol., 21: 357-372.

JØRGENSEN, T. MS 1988. Long-term changes in age at sexual maturity of the Northeast Arctic cod (Gadus morhua L.). ICES C.M. Doc. No. 1988/G:42, 32 p.

1990. Long-term changes in age at sexual maturity of Northeast Arctic cod (Gadus morhua L.). ICES J. Cons., 46: 235-248.

JUNQUERA, S., E. ROMAN, X. PAZ, and G. RAMILO. MS 1998. Changes in Greenland halibut growth, condition and fecundity in the Northwest Atlantic (Flemish Pass, Flemish Cap and southern Grand Bank). NAFO SCR Doc., No. 95, Serial No. N3096, 13 p.

KARLSEN, O., G. L. TARANGER, R. DAHLE, and B. NORBERG. 2000. Effects of exercise and continuous light on early sexual maturation in farmed Atlantic cod (Gadus morhua L.). In: Proceedings of the $6^{\text {th }}$ international symposium on the reproductive physiology of fish. B. Norberg, O. S. Kjesbu, G. L. Taranger, E. Andersson, and S. O. Stefansson (eds.). University of Bergen, Bergen, Norway. p. 328-330.

KASSEN, R., A. BUCKLING, G. BELL, and P. B. RAINEY. 2000. Diversity peaks at intermediate productivity in a laboratory microcosm. Nature, 406: 508-512.

KJESBU, O. S. 1989. The spawning activity of cod, Gadus morhua L. J. Fish Biol., 34: 195-206.

KJESBU, O. S., J. KLUNGSOYR, H. KRYVI, P. R. WITTHAMES, and M. GREER WALKER. 1991. Fecundity, atresia, and egg size of captive Atlantic cod (Gadus morhua) in relation to proximate body composition. Can. J. Fish. Aquat. Sci., 48: 2333-2343.

KJESBU, O. S., and H. KRYVI. 1989. Oogenesis in cod, 
Gadus morhua L., studied by light and electron microscopy. J. Fish Biol., 34: 735-746.

KJESBU, O. S., H. KRYVI, S. SUNDBY, and P. SOLEMDAL. 1992. Buoyancy variations in eggs of Atlantic cod (Gadus morhua L.) in relation to chorion thickness and egg size: Theory and observations. J. Fish Biol., 41: 581-599.

KJESBU, O. S., P. SOLEMDAL, P. BRATLAND, and M. FONN. 1996. Variation in annual egg production in individual captive Atlantic cod (Gadus morhua). Can. J. Fish. Aquat. Sci., 53: 610-620.

KJESBU, O. S., P. R. WITTHAMES, P. SOLEMDAL, and M. G. WALKER. 1998. Temporal variations in the fecundity of Arcto-Norwegian cod (Gadus morhua) in response to natural changes in food and temperature. J. Sea Res., 40: 303-321.

KJØRSVIK, E., K. HOEHNE, K. I. REITAN, and J. RAINUZZO. MS 1998. Evaluation of egg and larval quality criteria as predictive measures for juvenile production in turbot (Scophthalmus maximus L.). ICES C.M. Doc., No. 1998/L:19, 12 p.

KJØRSVIK, E., A. MANGOR-JENSEN, and I. HOLMEFJORD. 1990. Egg quality in fishes. Adv. Mar. Biol., 26: $71-114$.

KJØRSVIK, E., A. STENE, and S. LØNNING. 1984. Morphological, physiological and genetical studies of egg quality in cod (Gadus morhua L.). In: The propagation of cod Gadus morhua an international symposium. L. E. Dahl, D. S. Danielssen, E. Moksness, and P. Solemdal (eds.). Floedevigen Rapp., Arendal (Norway), Vol. 1, p. 67-86.

KNUTSEN, G. M., and S. TILSETH. 1985. Growth, development, and feeding success of Atlantic cod larvae Gadus morhua related to egg size. Trans. Am. Fish. Soc., 114: 507-511.

KORSBREKKE, K. 1999. Variations in maturity of haddock in the Barents Sea in relation to year-class strength, age, size, sex and area. J. Northw. Atl. Fish. Sci., 25: $37-45$.

KOSHELEV, B. V. 1984. Ecology of fish reproduction. Nauka Press, Moscow. p. 307 (in Russian).

KOSLOW, J. A., J. BELL, P. VIRTUE, and D. C. SMITH. 1995. Fecundity and its variability in orange roughy: Effects of population density, condition, egg size, and senescence. J. Fish. Biol., 47: 1063-1080.

KÖSTER, F. W., H. H. HINRICHSEN, D. SCHNACK, M. A. ST. JOHN, B. R. MACKENZIE, J. TOMKIEWICZ, C. MÖLlMANN, G. KRAUS, M. PliKSHS, A. MAKARCHOUK, and E. ARO. 2003. Recruitment of Baltic cod and sprat stocks: Identification of critical life stages and incorporation of environmental variability into stock recruitment relationships. Sci. Mar., 67(Suppl. 1): $129-154$.

KÖSTER, F. W., and C. MÖLLMANN. 2000. Trophodynamic control by clupeid predators on recruitment success in Baltic cod? ICES J. Mar. Sci., 57: 310-323.

KOSTYUCHENKO, V. A. 1961. Age and growth rate of Neogobius melanostomus (Pallas) in the Azov Sea. In: Proceedings of AzCher NIRO. M. Pishchepromizdat, Vol. 19, p. 45-60 (in Russian).
KOVTSOVA, M. V. MS 1987. Dynamics of the size-age structure and maturation of Arcto-Norwegian haddock in relation to year class strength fluctuations. ICES C.M. Doc., No. 1987/G:26, 12 p.

KRAUS, G., A. MUELLER, and F. W. KÖSTER. MS 1997. Intra- and interannual variability in fecundity of Baltic cod. ICES C.M. Doc., No. 1997/CC:13, 15 p.

KRAUS, G., A. MUELler, K. TRELlA, and F. W. KÖSTER. 2000. Fecundity of Baltic cod: temporal and spatial variation. J. Fish Biol., 56: 1327-1341.

KRAUS, G., J. TOMKIEWICZ, and F. W. KÖSTER. 2002. Egg production of Baltic cod (Gadus morhua) in relation to variable sex ratio, maturity, and fecundity. Can. J. Fish. Aquat. Sci., 59: 1908-1920.

KRYZHANOVSKY, S. G. 1949. Ecological and morphological regularities of development of Cyprinoidei and Siluroidei. In: Proceedings of the Institute of Morphology of Animals. USSR Academy of Science Press. M.-L., p. 5-332 (in Russian).

KURITA, Y., A. THORSEN, M. FONN, A. SVARDAL, and O. S. KJESBU. 2000. Oocyte growth and fecundity regulation of Atlantic herring (Clupea harengus) in relation to declining body reserves during overwintering. In: Proceedings of the 6th international symposium on the reproductive physiology of fish. B. Norberg, O. S. Kjesbu, G. L. Taranger, E. Andersson, and S. O. Stefansson (eds.). Bergen, Norway. p. 85-87.

LAINE, P., J. EKLUND, and M. SOIKKELI. 1998. Reproduction of Baltic herring after dissimilar growth and overwintering seasons. Ophelia, 48: 155-165.

LAINE, P., and M. RAJASILTA. 1999. The hatching success of Baltic herring eggs and its relation to female condition. J. Exp. Mar. Biol. Ecol., 237: 61-73.

LAMBERT, Y., and J. D. DUTIL. 1997a. Can simple condition indices be used to monitor and quantify seasonal changes in the energy reserves of Atlantic cod (Gadus morhua)? Can. J. Fish. Aquat. Sci., 54(Suppl. 1): 104-112.

1997b. Condition and energy reserves of Atlantic cod (Gadus morhua) during the collapse of the northern Gulf of St. Lawrence stock. Can. J. Fish. Aquat. Sci., 54: 2388-2400.

2000. Energetic consequences of reproduction in Atlantic cod (Gadus morhua) in relation to spawning level of somatic energy reserves. Can. J. Fish. Aquat. Sci., 57: 815-825.

LAMBERT, Y., J. D. DUTIL, and P. OUELLET. 2000. Nutritional condition and reproductive success in wild fish populations. In: Proceedings of the 6 th international symposium on the reproductive physiology of fish. B. Norberg, O. S. Kjesbu, G. L. Taranger, E. Andersson, E. and S. O. Stefansson (eds.). Bergen, Norway. p. $77-84$.

LAPIN, Y. E., and Y. G. YUROVITSKY. 1959. On the intraspecific regularities of fish maturation and fecundity dynamics. J. Gen. Biol., 20: 439-446 (in Russian).

MA, Y., O. S. KJESBU, and T. JERGENSEN. 1998. Effects of ration on the maturation and fecundity in captive Atlantic herring (Clupea harengus). Can. J. Fish. Aquat. Sci., 55: 900-908. 
MAACK, G., and M. R. GEORGE. 1999. Contributions to the reproductive biology of Encrasicholina punctifer Fowler, 1938 (Engraulidae) from West Sumatra, Indonesia. Fish. Res., 44: 113-120.

MACKENZIE, B. R., H. H. HINRICHSEN, M. PLIKSHS, K. WIELAND, and A. S. ZEZERA. 2000. Quantifying environmental heterogeneity: Habitat size necessary for successful development of cod Gadus morhua eggs in the Baltic Sea. Mar. Ecol. Prog. Ser., 193: 143-156.

MAKEEVA, F. P., and G. V. NIKOLSKY. 1965. Sexual structure of fish spawning population, its adaptive significance and ways of regulation. In: Theoretical basis of fish farming. G. V. Nikolsky (ed.). Nauka Press, Moscow, p. 53-72 (in Russian).

MALMBERG, S. A. 1986. The ecological impact of the East Greenland Current of the North Icelandic waters. In: The role of freshwater outflow in coastal marine ecosystems. S. Skreslet (ed.). NATO Adv. Stud. Inst. Ser., Ser. G, Ecol. Sci., 7: 389-404.

MARSHALL, C. T., O. S. KJESBU, N. A. YARAGINA, P. SOLEMDAL, and Ø. ULLTANG. 1998. Is spawner biomass a sensitive measure of the reproductive and recruitment potential of northeast Arctic cod? Can. J. Fish. Aquat. Sci., 55: 1766-1783.

MARSHALL, C.T., L. O'BRIEN, J. TOMKIEWICZ, G. MARTEINSDOTTIR, M. J. MORGAN, F. SABORIDOREY, F.W. KÖSTER, J. L. BLANCHARD, D.H. SECOR, G. KRAUS, P.J. WRIGHT, N.V. MUKHINA, and H. BJÖRNSSON. 2003. Developing alternative indices of reproductive potential for use in fisheries management: case studies for stocks spanning an information gradient. J. Northw. Atl. Fish. Sci., 33: 161-190 (this volume).

MARSHALL, C. T., N. A. YARAGINA, Y. LAMBERT, and O. S. KJESBU. 1999. Total lipid energy as a proxy for total egg production by fish stocks. Nature, 402: 288-290.

MARTEINSDOTTIR, G., and G. BEGG. 2002. Essential relationships incorporating the influence of age, size and condition on variables required for estimation of reproductive potential in Atlantic cod Gadus morhua stocks. Mar. Ecol. Prog. Ser., 235: 235-256.

MARTEINSDOTTIR, G., and H. BJÖRNSSON. MS 1999. Time and duration of spawning of cod in Icelandic waters. ICES C.M. Doc., No. 1999/Y:34, 22 p.

MARTEINSDOTTIR, G., and A. STEINARSSON. 1998. Maternal influence on the size and viability of Iceland cod Gadus morhua eggs and larvae. J. Fish Biol., 52: 1241-1258.

MARTEINSDOTTIR, G., and K. THORARINSSON. 1998. Improving the stock-recruitment relationship in Icelandic cod (Gadus morhua) by including age diversity of spawners. Can. J. Fish. Aquat. Sci., 55: 1372-1377.

MCEDWARD, L. R., and S. F. CARSON. 1987. Variation in egg organic content and its relationship with egg size in the starfish Solaster stimpsoni. Mar. Ecol. Prog. Ser., 37: 159-169.

MCEDWARD, L. R., and K. H. MORGAN. 2001. Interspecific relationships between egg size and the level of parental investment per offspring in echinoderms. Biol. Bull. Mar. Biol. Lab. Woods Hole, 200: 33-50.

MCEVOY, L. A., and J. MCEVOY. 1991. Size fluctuation in the eggs and newly hatched larvae of captive turbot (Scophthalmus maximus ). J. Mar. Biol. Assoc. U.K., 71: 679-690.

MESSIATZEVA, E. 1932. Chief results of the fishery research in the Barents Sea in 1930 by the GOIN (State Oceanographical Institute of USSR). ICES Rapp. Proc.Verb., 81(Append. 3): 141-151.

MILLER, T. J., J. HERRA, and W. C. LEGGETT. 1995. An individual-based analysis of the variability of eggs and their newly hatched larvae of Atlantic cod (Gadus morhua) on the Scotian Shelf. Can. J. Fish. Aquat. Sci., 52: 1083-1093.

MILLNER, R., C. WHITING, M. GREER WALKER, and P. WITTHAMES. 1991. Growth increment, condition and fecundity in sole (Solea solea (L.)) from the North Sea and eastern English Channel. Neth. J. Sea Res., 27: 433-439.

MILTON, D. A., S. J. M. BLABER, and N. J. F. RAWLINSON. 1995. Fecundity and egg production of four species of short-lived clupeoid from Solomon Islands, Tropical South Pacific. ICES J. Mar. Sci., 52: 111-125.

MORK, J., R. GISKEOEDEGAARD, and G. SUNDNESS. 1984. The haemoglobin polymorphism in Atlantic cod (Gadus morhua L.): Genotypic differences in somatic growth and in maturing age in natural populations. In: The propagation of cod Gadus morhua L. an international symposium. E. Dahl, D. S. Danielssen, E. Moksness and P. Solemdal (eds.). Floedevigen Rapp., Arendal (Norway). p. 721-732.

MURUA, H., G. KRAUS, F. SABORIDO-REY, P. R. WITTHAMES, A. THORSEN, and S. JUNQUERA. 2003. Procedures to estimate fecundity of marine fish species in relation to their reproductive strategy. J. Northw. Atl. Fish. Sci. 33: 33-54 (this volume).

MURUA, H., and F. SABORIDO-REY. 2003. Female reproductive strategies of marine fish species of the North Atlantic. J. Northw. Atl. Fish. Sci. 33: 23-31(this volume).

MYERS, R. A., G. MERTZ, and P. S. FOWLOW. 1997. Maximum population growth rates and recovery times for Atlantic cod, Gadus morhua. Fish. Bull. U.S., 95: $762-772$.

NELSON, K., and M. SOULÉ. 1987. Genetical conservation of exploited fishes. In: Population genetics and fishery management. N. Ryman and F. Utter (eds.). University of Washington Press, Seattle, p. 345-368.

NEUMANN, R. M., and B. R. MURPHY. 1992. Seasonal relationships of relative weight to body composition in white crappie, Pomoxis annularis Rafinesque. Aquacult. Fish. Manag., 23: 243-251.

NIKOLSKY, G. V. 1969. Fish population dynamics. Oliver and Boyd, Edinburgh. 323 p.

NISSLING, A. 1994. Survival of eggs and yolk-sac larvae of Baltic cod (Gadus morhua L.) at low oxygen levels in different salinities. ICES Mar. Sci. Symp., 198: 626-631. 
NISSLING, A., H. KRYVI, and L. VALLIN. 1994. Variation in egg buoyancy of Baltic cod Gadus morhua and its implications for egg survival in prevailing conditions in the Baltic Sea. Mar. Ecol. Prog. Ser., 110: 67-74.

NISSLING, A., R. LARSSON, L. VALLIN, and K. FROHLUND. 1998. Assessment of egg and larval viability in cod, Gadus morhua: methods and results from an experimental study. Fish. Res., 38: 169-186.

NISSLING, A., L. WESIN, and O. HJERNE. MS 2000. Spawning success in relation to salinity of three flatfish species, dab (Pleuronectes limanda), plaice (Pleuronectes platessa) and flounder (Pleuronectes flesus), in the brackish water Baltic sea. ICES C.M.Doc., No. 2000/R:05, 26 p.

NISSLING, A., and L. WESTIN. 1991. Egg mortality and hatching rate of Baltic cod (Gadus morhua) in different salinities. Mar. Biol., 111: 29-32.

1997. Salinity requirements for successful spawning of Baltic and Belt Sea cod and the potential for cod stock interactions in the Baltic Sea. Mar. Ecol. Prog. Ser, 152: 261-271.

NORBERG, B., V. VALKNER, J. HUSE, I. KARLSEN, and G. LEROEY GRUNG. 1991. Ovulatory rhythms and egg viability in the Atlantic halibut (Hippoglossus hippoglossus). Aquaculture, 97: 365-371.

O'BRIEN, L. 1999. Factors influencing the rate of sexual maturity and the effect on spawning stock for Georges Bank and Gulf of Maine Atlantic cod Gadus morhua stocks. J. Northw. Atl. Fish. Sci., 25: 179-203.

OGANESYAN, S. A. MS 1993. Periodicity of the Barents Sea cod reproduction. ICES C.M. 1993/G:64, 11 p.

OOSTHUIZEN, E., and N. DAAN. 1974. Egg fecundity and maturity of North Sea cod, Gadus morhua. Neth. J. Sea Res., 8: 378-397.

OSKARSSON, G. J., O. S. KJESBU, and A. SLOTTE. 2002. Predictions of realised fecundity and spawning time in Norwegian spring-spawning herring (Clupea harengus). J. Sea Res., 48: 59-79.

OUELLET, P., Y. LAMBERT, and I. BÉRUBÉ. 2001. Cod egg characteristics and viability in relation to low temperature and maternal nutritional condition. ICES J. Mar. Sci., 58: 672-686.

PEDERSEN, G. I., J. GERUP, L. NILSSON, J. R. LARSEN, and R. SCHNEIDER. MS 1997. Body burdens of lipophilic xenobiotics and reproductive success in Baltic cod (Gadus morhua L.). ICES C.M. Doc., No. 1997/U:10, 22 p.

PEPIN, D. C., D. C. ORR, and J. T. ANDERSON. 1997. Time to hatch and larval size in relation to temperature and egg size in Atlantic cod (Gadus morhua). Can. J. Fish. Aquat. Sci., 54(Suppl. 1): 2-10.

PICKOVA, J., P. C. DUTTA, P. O. LARSSON, and A. KIESSLING. 1997. Early embryonic cleavage pattern, hatching success, and egg-lipid fatty acid composition: Comparison between two cod (Gadus morhua) stocks. Can. J. Fish. Aquat. Sci., 54: 2410-2416.

PLIKSHS, M., M. KALEJS, and G. GRAUMAN. MS 1993. The influence of environmental conditions and spawning stock size on the year-class strength of the eastern Baltic cod. ICES C.M. Doc., No. 1993/J:22, 13 p.
POLICANSKY, D. 1983. Size, age and demography of metamorphosis and sexual maturation in fishes. $\mathrm{Am}$. Zool., 23: 57-63.

PONOMARENKO, I. Y., and N. A. YARAGINA. MS 1994. Maturity rate of the Lofoten-Barents Sea cod in 40'S and 90'S. ICES C.M. Doc., No. 1994/G:30, 17 p.

PRAIRIE, Y. T. 1996. Evaluating the predictive power of regression models. Can. J. Fish. Aquat. Sci., 53: 490-492.

RAKITIN, A., M. M. FERGUSON, and E. A. TRIPPEL. 1999. Sperm competition and fertilization success in Atlantic cod (Gadus morhua): effects of sire size and condition factor on gamete quality Can. J. Fish. Aquat. Sci., 56: 2315-2323.

RASS, T. S. 1948. On periods of life and regularities of development and growth in fishes. In: Proceedings the USSR Academy of Science. Biological Series, p. 295-305 (in Russian).

REZNICK, D. A., H. BRYGA, and J. A. ENDLER. 1990. Experimentally induced life-history evolution in a natural population. Nature, 346: 357-359.

REZNICK, D. N., F. H. SHAW, F. H. RODD, and R. G. SHAW. 1997. Evaluation of the rate of evolution in natural populations of guppies (Poecilia reticulata). Science, 275: 1934-1937.

RICKER, W. E. 1981. Changes in the average size and average age of Pacific salmon. Can. J. Fish. Aquat. Sci., 38: 1636-1656.

RIDEOUT, R. M., M. P. M. BURTON, and G. A. ROSE. 2000. Observations on mass atresia and skipped spawning in northern Atlantic cod, from Smith Sound, Newfoundland. J. Fish. Biol., 57: 1429-1440.

RIJNSDORP, A. D. 1990. The mechanism of energy allocation over reproduction and somatic growth in female North Sea plaice, Pleuronectes platessa L. Neth. J. Sea Res., 25: 279-290.

1991. Changes in fecundity of female North Sea plaice (Pleuronectes platessa L.) between three periods since 1900. ICES J. Mar. Sci., 48: 253-280.

1993a. Relationship between juvenile growth and the onset of sexual maturity of female North Sea plaice, Pleuronectes platessa. Can. J. Fish. Aquat. Sci., 50: 1617-1631.

1993b. Fisheries as a large-scale experiment on lifehistory evolution: Disentangling phenotypic and genetic effects in changes in maturation and reproduction of North Sea plaice, Pleuronectes platessa L. Oecologia, 96: 391-401.

RIJNSDORP, A. D., N. DAAN, F. BEEK, and H. J. L. HEESSEN. 1991. Reproductive variability in North Sea plaice, sole, and cod. ICES J. Cons., 47: 352-375.

ROENNEBERG, J. E., A. C. GUNDERSEN, and J. BOJE. MS 1998. Fecundity of Greenland halibut (Reinhardtius hippoglossides Walbaum) in East Greenlandic waters. ICES C.M.Doc., No. 1998/O:26, 12 p.

ROFF, D. A. 1982. Reproductive strategies in flatfish: A first synthesis. Can. J. Fish. Aquat. Sci., 39: 1686-1698.

1984. The evolution of life history parameters in teleosts. Can. J. Fish. Aquat. Sci., 41: 989-1000.

ROWE, D. K., J. E. THORPE, and A. M. SHANKS. 1991. Role of fat stores in the maturation of male Atlantic 
salmon (Salmo salar) parr. Can. J. Fish. Aquat. Sci., 48: 405-413.

SABORIDO-REY, F., and S. JUNQUERA. 1998. Histological assessment of variations in sexual maturity of cod (Gadus morhua L.) at the Flemish Cap (north-west Atlantic). ICES J. Mar. Sci., 55: 515-521.

SHATUNOVSKY, M. I. 1978. Annual balance of matter and energy in some age-groups of cod, haddock, Baltic herring and flounder. In: Problems of fish physiology. Proceedings of VNIRO, p. 13-19 (in Russian).

1980. Ecological and physiological investigations of fish ontogenesis. In: Ecology of reproduction and development in fish. Znanie Press, Moscow, p. 29-47 (in Russian).

SHATUNOVSKY, M. I., N. V. AKIMOVA, and G. I. RUBAN. 1996. Responce of fish reproductive system on the anthropogenous influence. J. Ichthyol., 36: 229-238 (in Russian).

SHIELDS, R. J., N. P. BROWN, and N. R. BROMAGE. 1997. Blastomere morphology as a predictive measure of fish egg viability. Aquaculture, 155: 1-12.

SHULMAN, G. E. 1974. Life cycles of fish. John Wiley, New York, $257 \mathrm{p}$.

SOLEMDAL, P. MS 1970. The reproductive adaptation of marine teleosts to water of low salinity. ICES C.M. Doc., No. 1970/F:30, 12 p.

1997. Maternal effects - A link between the past and the future. J. Sea Res., 37: 213-227.

SOLEMDAL, P., O. BERGH, I. B. FALK-PETERSEN, H. J. FYHN, O. GRAHL-NIELSEN, J. M. HAALAND, O. S. KJESBU, E. KJOERSVIK, S. LOEKEN, I. OPSTAD, T. PEDERSEN, A. B. SKIFTESVIK, A. THORSEN, and G. DAHLE. MS 1993. Size of spawning Arcto-Norwegian cod (Gadus morhua L.) and the effects on their eggs and early larvae. ICES C.M. Doc., No. 1993/G:41, 13 p.

SOLEMDAL, P., O. BERGH, R. N. FINN, H. J. FYHN, O. GRAHL-NIELSEN, O. HOMME, O. S. KJESBU, E. KJOERSVIK, I. OPSTAD, and A. B. SKIFTESVIK. MS 1992a. The effects of maternal status of ArctoNorwegian cod on egg quality and vitality of early larvae. II. Preliminary results of the experiment in 1992. ICES C.M. Doc., No. 1992/G:79, 19 p.

SOLEMDAL, P., O. S. KJESBU, and M. FONN. MS 1995. Egg mortality in recruit- and repeat-spawning cod - an experimental study. ICES C.M. Doc., No. 1995/G:35, $13 \mathrm{p}$.

SOLEMDAL, P., O. S. KJESBU, and E. KJOERSVIK. MS $1992 \mathrm{~b}$. The effects of maternal status of ArctoNorwegian cod on egg quality and vitality of early larvae. I. The collection and characteristics of the cod females, a pilot study. ICES C.M. Doc., No. 1992/G:78, 8 p.

STEARNS, S. C., and R. E. CRANDALL. 1984. Plasticity for age and size at sexual maturity: a life-history response to unavoidable stress. In: Fish reproduction: strategies and tactics. G. W. Potts and R. J. Wootton (eds.). Academic Press, London, UK, p. 13-33.

STORE. 2000. Environmental and fisheries influences on fish stock recruitment in the Baltic Sea. EU-Project
FAIR CT98 3959, Consolidated Progress Report, Part $I, 220 \mathrm{p}$.

TAGGART, C. T., J. ANDERSON, C. BISHOP, E. COLBOURNE, J. HUTCHINGS, G. LILLY, J. MORGAN, E. MURPHY, R. MYERS, G. ROSE, and P. SHELTON. 1994. Overview of cod stocks, biology, and environment in the Northwest Atlantic region of Newfoundland, with emphasis on northern cod. ICES Mar. Sci. Symp., 198: 140-157.

TANASICHUK, R. W., and D. M. WARE. 1987. Influence of interannual variations in winter sea temperature on fecundity and egg size in Pacific herring (Clupea harengus pallasi). Can. J. Fish. Aquat. Sci., 44: 1485-1495.

THORPE, J. E. 1986. Age at first maturity in Atlantic salmon, Salmo salar: Freshwater period influences and conflicts with smolting. In: Salmonid age at maturity. D. J. Meerburg (ed.). Can. Spec. Publ. Fish. Aquat. Sci., 89: 7-14.

1994. Performance thresholds and life-history flexibility in salmonids. Conserv. Biol., 8: 877-879.

THORPE, J. E., M. MANGEL, N. B. METCALFE, and F. A. HUNTINGFORD. 1998. Modelling the proximate basis of salmonid life-history variation, with application to Atlantic salmon, Salmo salar L. Evol. Ecol., 12: 581-599.

THORPE, J. E., C. TALBOT, and C. VILLARREAL. 1982. Bimodality of growth and smolting in Atlantic salmon, Salmo salar L. Aquaculture, 28: 123-132.

TOMKIEWICZ, J., and F. W. KÖSTER. MS 1999. Maturation processes and spawning time of cod in the Bornholm Basin of the Baltic Sea: preliminary results. ICES C.M. Doc., No. 1999/Y:25, 19 p.

TOMKIEWICZ, J., M. J. MORGAN, J. BURNETT, and F. SABORIDO-REY. 2003. Available information for estimating reproductive potential of Northwest Atlantic groundfish stocks. J. Northw. Atl. Fish. Sci., 33: 1-21 (this volume).

TRIPPEL, E. A. 1995. Age at maturity as a stress indicator in fisheries. BioScience, 45: 759-771.

1998. Egg size and viability and seasonal offspring production of young Atlantic cod. Trans. Am. Fish. Soc., 127: 339-359.

2003. Estimation of male reproductive success of marine fish. J. Northw. Atl. Fish. Sci., 33: 81-113 (this volume).

TRIPPEL, E. A., O. S. KJESBU, and P. SOLEMDAL. 1997b. Effects of adult age and size structure on reproductive output in marine fishes. In: Early life history and recruitment in fish populations. R. C. Chambers and E. A. Trippel (eds.). Chapman and Hall, New York, p. 63-102.

TRIPPEL, E. A., M. J. MORGAN, A. FRÉCHET, C. ROLLET, A. SINCLAIR, C. ANNAND, D. BEANLANDS, and L. BROWN. 1997a. Changes in age and length at sexual maturity of Northwest Atlantic cod, haddock and pollock stocks, 1972-1995. Can. Tech. Rep. Fish. Aquat. Sci., 2157, 132 p.

TRIPPEL, E. A., and J. D. NEILSON. 1992. Fertility and 
sperm quality of virgin and repeat-spawning Atlantic cod (Gadus morhua) and associated hatching success. Can. J. Fish. Aquat. Sci., 49: 2118-2127.

TYLER, A. V., and R. S. DUNN. 1976. Ration, growth, and measures of somatic and organ condition in relation to meal frequency in winter flounder, Pseudopleuronectes americanus, with hypothesis regarding population homeostasis. J. Fish. Res. Board Can., 33: 63-75.

TYLER, C. R., and J. P. SUMPTER. 1996. Oocyte growth and development in teleosts. Rev. Fish Biol. Fish., 6: 287-318.

VALLIN, L. MS 1999. Environmental bottlenecks for reproduction of Baltic cod, Gadus morhua. Doctoral dissertation, University of Stockholm, Sweden, $117 \mathrm{p}$.

VALLIN, L., and A. NISSLING. 2000. Maternal effects on egg size and egg buoyancy of Baltic cod, Gadus morhua: Implications for stock structure effects on recruitment. Fish. Res., 49: 21-37.

WALSH, S. J., and M. J. MORGAN. 1999. Variation in maturation of yellowtail flounder (Pleuronectes ferruginea) on the Grand Bank. J. Northw. Atl. Fish. Sci., 25: 47-59.

WALSH, S. J., R. WELLS, and S. BRENNAN. MS 1986. Histological and visual observations on oogenesis and sexual maturity of Flemish Cap female cod. NAFO SCR Doc., No. 111, Serial No. 1238, 11 p.

WARE, D. M. 1977. Spawning time and egg size of Atlantic mackerel, Scomber scombrus, in relation to the plankton. J. Fish. Res. Board Can., 34: 2308-2315.

WELCH, D. W., and R. P. FOUCHER. 1988. A maximum likelihood methodology for estimating length-atmaturity with application to Pacific cod (Gadus macrocephalus) population dynamics. Can. J. Fish. Aquat. Sci., 45: 333-343.

WESTIN, L., and A. NISSLING. 1991. Effects of salinity on spermatozoa motility, percentage of fertilized eggs and egg development of Baltic cod (Gadus morhua), and implications for cod stock fluctuations in the Baltic. Mar. Biol., 108: 5-9.

WESTRHEIM, S. J. 1987. Parabranchial X-cell lesions in trawl-caught Pacific cod (Gadus macrocephalus) off the west coast of Canada - incidence and effects. Can. Tech. Rep. Fish. Aquat. Sci., 1593, 49 p.

WIELAND, K., A. JARRE-TEICHMANN and K. HORBOWA. 2000. Changes in the timing of spawning of Baltic cod: possible causes and implications for recruitment. ICES J. Mar. Sci., 57: 452-464.

WIELAND, K., U. WALLER, and D. SCHNACK. 1994. Development of Baltic cod eggs at different levels of temperature and oxygen content. Dana, 10: 163-177.

WILES, M., and A. W. MAY. 1968. Biology and fishery of the West Newfoundland cod stock. ICNAF Res. Bull., 5: 5-43.

WINTERS, G. H., J. P. WHEELER, and D. STANSBURY. 1993. Variability in the reproductive output of springspawning herring in the north-west Atlantic. ICES J. Mar. Sci., 50: 15-25.

WITTHAMES, P. R., M. GREER WALKER, M. T. DINIS, and C. L. WHITING. 1995. The geographical variation in the potential annual fecundity of Dover sole Solea solea (L.) from European shelf waters during 1991. Neth. J. Sea Res., 34: 45-58.

WOOTTON, R. J. 1979. Energy costs of egg production and environmental determinants of fecundity in teleost fishes. Symp. Zool. Soc. Lond., 44: 133-159.

1992. Constraints in the evolution of fish life histories. Neth. J. Zool., 42: 291-303.

1999. Ecology of teleost fishes, 2nd edition. Kluwer Academic Publishers, 386 p.

WRIGHT, P. J. 1990. The reproductive strategy of Stolephorus heterolobus in the South Java Sea. In: Tuna baitfish in the Indo-Pacific Region. S. J. M. Blaber, and J. Copland (eds.). ACIAR Proceedings No. 30, p. 83-88.

WROBLEWSKI, J. S., H. W. HISCOCK, and I. R. BRADBURY. 1999. Fecundity of Atlantic cod (Gadus morhua) farmed for stock enhancement in Newfoundland bays. Aquaculture, 171: 163-180.

YAMADA, T., I. AOKI, and I. MITANI. 1998. Spawning time, spawning frequency and fecundity of Japanese chub mackerel, Scomber japonicus in the waters around the Izu Islands, Japan. Fish. Res., 38: 83-89.

YARAGINA, N. A., and C. T. MARSHALL. 2000. Trophic influences on interannual and seasonal variation in the liver condition index of Northeast Arctic cod (Gadus morhua). ICES J. Mar. Sci., 57: 42-55.

ZAMAKHAEV, D. F. 1964. On the influence of the growth in the first years of life on further growth in fish. In: Papers on the methods of the estimation of stocks and catch prediction. T. F. Dementyeva (ed.). Proceedings of VNIRO, Moscow. p. 109-142 (in Russian; English translation: Fish. Res. Board Can. Transl., Ser. No. 549), $39 \mathrm{p}$. 